\title{
A Scramjet Compression System for Hypersonic Air Transportation Vehicle Combined Cycle Engines
}

\author{
Devendra Sen ${ }^{1}$, Apostolos Pesyridis ${ }^{1,2, *}$ and Andrew Lenton ${ }^{1}$ \\ 1 Centre for Advanced Powertrain and Fuels Research (CAPF), Department of Mechanical, Aerospace and \\ Civil Engineering, Brunel University, London UB8 3PH, UK; 1207660@brunel.ac.uk (D.S.); \\ 1306257@brunel.ac.uk (A.L.) \\ 2 Metapulsion Engineering Limited, Northwood, Middlesex HA63LG, UK \\ * Correspondence: a.pesyridis@brunel.ac.uk; Tel.: +44-1895-267-901
}

Received: 1 May 2018; Accepted: 10 June 2018; Published: 14 June 2018

\begin{abstract}
This paper proposes a compression system for a scramjet, to be used as part of a combined cycle engine on a hypersonic transport vehicle that can achieve sustained flight at 8 Mach 8 . Initially research into scramjet compression system and shock wave interaction was conducted to establish the foundation of the scramjet inlet and isolator sections. A Computational Fluid Dynamics (CFD) campaign was conducted, where the shock structure and flow characteristics was analysed between Mach 4.5-8. The compression system of a scramjet is of crucial importance in providing air at suitable Mach number, pressure and temperature to the combustion chamber. The use of turbojet engines in over-under configuration with the scramjet was investigated as well as the study of a combined cycle scramjet-ramjet configuration. It was identified that locating the scramjet in the centre with a rotated ramjet on either side, where its ramps make up the scramjet wall was the most optimal configuration, as it mitigated the effect of the oblique shocks propagating from the scramjet walls into the adjacent ramjet. Furthermore, this meant that the forebody of the vehicle could solely be used as the compression surface by the scramjet. In this paper, the sizing of the scramjet combustion chamber and nozzle were modified to match the flow properties of the oncoming flow with the purpose of producing the most optimum scramjet configuration for the cruise speed of Mach 8. CFD simulations showed that the scramjet inlet did not provide the levels of compression and stagnation pressure recovery initially required. However, it was found that the scramjet provided significantly more thrust than the drag of the aircraft at sustained Mach 8 flight, due to its utilisation of a very aerodynamic vehicle design.
\end{abstract}

Keywords: scramjet; ramjet; hypersonic; combustion; hypersonic engine integration; combined cycle engine; Computational Fluid Dynamics (CFD)

\section{Introduction}

Hypersonic travel in years has seen increasing research interest by the aerospace sector due to its potential in military as well as increasingly in civilian applications. Hypersonic air-breathing propulsion vehicles in particular offer a replacement for the conventional subsonic modes of commercial transport with a new class of flight vehicles that can offer time-saving means of transportation for long range flights.

Typically, due to the wide range of flight speeds involved (Mach number > 5) combined-cycle propulsion architectures are being proposed encompassing combinations of gas turbines, ramjets and scramjets as well as rockets. In this work, one such combined cycle system comprising of a gas turbine, ramjet and scramjet architecture was investigated, focusing on the design aspect of the scramjet compression system. 
A supersonic combustion ramjet or scramjet is a ramjet variant where the airflow remains supersonic as it passes through the engine including in the combustor whereas in the ramjet flow is decelerated to subsonic velocity for combustion. A typical scramjet consists of a converging inlet, isolator, combustion chamber and a diverging nozzle. Compared to gas turbines, ramjets and scramjet engines do not have any internal moving parts; an advantage of this is that the internal geometry does not have to be symmetric along the central axis.

Since there is no mechanical system to compress air for combustion, ramjet and scramjet engines rely on the high-kinetic energy from the high velocity freestream air and oblique shock waves to provide compression of the oncoming flow to suitable pressure, temperature and density; this is known as the ramming effect and is essential for efficient combustion [1]. One disadvantage of using the geometry of the ramjet and scramjet to compress the oncoming airflow is that the geometry is fixed for a specific flight speed and operating outside this design point can lead to inefficiency in compression of the flow, resulting in excessive fuel usage. This issue can be solved by having a variable geometry inlet, but may be difficult to implement especially if the flight speed range is large.

For flight speeds above about Mach 5 a scramjet is used, as opposed to a ramjet as decreasing the air velocity to subsonic speeds does not actually provide any benefit instead causing air pressure to rise significantly leading to structural design implications as well as excessive heat transfer which would be experienced at the walls of the combustion chamber because of the conversion of the kinetic energy of the flow to thermal energy when decelerated to zero velocity at the walls (conservation of energy). Hence the geometry of a scramjet must be designed differently than for a ramjet; this is done by controlling the shock wave stemming from the aircraft's forebody [2].

Scramjet operating altitudes are limited between the increased skin friction and high temperature operating limitations imposed by low altitude flight and the lack of oxygen at very high altitudes with the "sweet spot" being approximately 100,000 ft [3].

Since ramjet and scramjet engines cannot operate at low freestream velocities other propulsion systems are required to propel the aircraft to the correct speed and altitude for ramjet $(2.5<\mathrm{M}<5)$ and later scramjet $(M>5)$ engagement. The use of air-breathing engines such as a turboramjet/scramjet is also potentially the more commercially viable method to power an aircraft at hypersonic speed for long periods of time because unlike a rocket, air-breathing engine do not require an additional oxidiser on board [4].

This paper is a technical investigation into the design requirements and subsequent performance of a scramjet compression system as part of a range of combined-cycle architectures. The work is novel in that it addresses the detailed design and computational campaigns associated with a series of combined cycle architectures to optimise the performance of the propulsion system. As such it is attempted to add to the current sporadic nature of the literature. It is a detailed analysis unlike most papers to be found in this futuristic and still relatively niche area.

In the following sections, the paper will deal with the theoretical background, 2-D and 3-D CFD simulations carried out in the effort to arrive at an appropriate scramjet compression system as part of a Mach 8-capable combined cycle engine. This paper addresses the scarcity in literature regarding the availability of detailed computational investigations into the design of scramjet inlet compression systems for hypersonic propulsion.

\section{Scramjet Theory}

This section will provide the necessary theory needed to analyse the key parameters required to design the scramjet compression system. Figure 1 presents the different flow stations of a scramjet. Breaking the engine down into the separate functional components allows us to identify the phenomena that undergoes at each engine segment [2]:

1. Compression section (Station 0 to 3):

$>$ Station 0 refers to the freestream flow just before it passes through the first shockwave. 
$>\quad$ Station 1 refers to the end of the forebody of the vehicle.

$>\quad$ Station 2 is the end of the inlet compression surfaces.

$>\quad$ The region between the Stations 2 and 3 is known as the isolator, which contains the shock train.

2. Combustion section (Stations 3 to 4 ): Between station 3 and 4 is the combustion chamber where fuel is injected at supersonic velocity into the airflow, the fuel self-ignites due to the extreme pressure and temperature of the oncoming compressed flow.

3. Expansion section (Stations 4 to 10): Between station 4 and 9 is the nozzle where expansion takes place internally. Station 9 and 10 is the external expansion surfaces, which makes up the vehicle's aft.

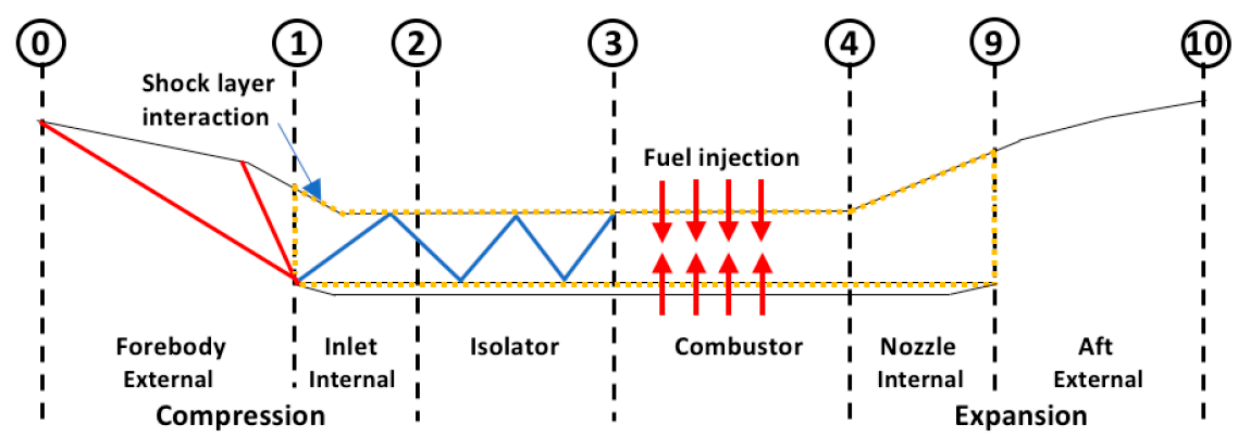

Figure 1. Flow stations in a scramjet engine.

\subsection{Compression Section (Station 0 to 3)}

The vehicle's forebody plays a huge role in providing surfaces for adequate air mass capture as the surface area required is not sufficiently provided by just the inlet surfaces. The geometry of the compression section is one of the most important aspects of a scramjet engine as it needs to compress and decelerate the oncoming flow to provide 'good quality' air to the combustion system; where good implies suitable pressure, temperature and at the correct mass flow rate.

There are several usable compression methods, which depend on the requirements of the vehicle; these types are:

(1) External compression;

(2) Mixed compression;

(3) Internal Compression;

Figure 2a displays an external compression system where all the oblique shock waves are generated outside of the engine cowl, these oblique shocks combine and focus on the lip of the cowl. Since there are no other oblique shocks present inside the engine, the flow downstream from the final oblique shock is uniform and parallel with the walls [2]. An oblique shock wave is when a shock wave is inclined to the flow direction as opposed to normal shock waves which are perpendicular to the streamlines [5]. The uncaptured flow is forced to turn due to the existence of the cowl, this flow is turned the same angle as the flow entering the engine.

Figure $2 \mathrm{~b}$ depicts an example of a mixed compression system i.e., a combination of external and internal compression surfaces; the converging inlet incorporates various bends in the geometry to turn the flow generating oblique shock waves so as to allow compression and deceleration of the flow to take place. This method of mixed compression systems can contain several 'weaker' oblique shocks in the internal section of the compression surfaces to produce the same downstream flow properties as just the external compression inlet. A disadvantage is that this results in increasing the length of the compression system but allows for a better shock train structure to develop in the isolator. 
Figure 3 illustrates an example of a symmetrical internal compression system, where there is a line of symmetry along the centreline. It relies on combining oblique shockwaves to generate a uniform and parallel streamwise flow, thus the axial length can be shortened to obtain an adequate amount of compression. One detrimental issue with this system is that the extra compression surface can facilitate the generation of complex flows when the vehicle is not flying at its design speed, consequently the flow at the lower end spills below the notched cowl. Flow spillage (therefore spillage drag) decreases as the vehicle reaches closer to the design speed [6].

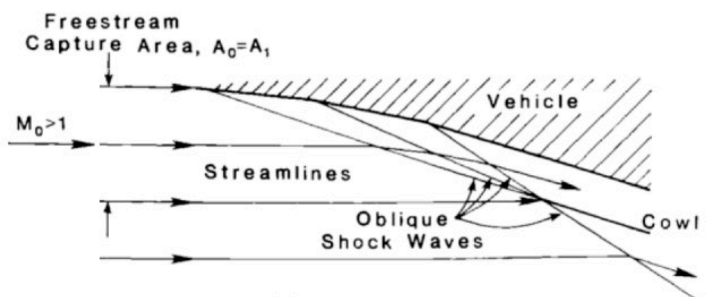

(a)

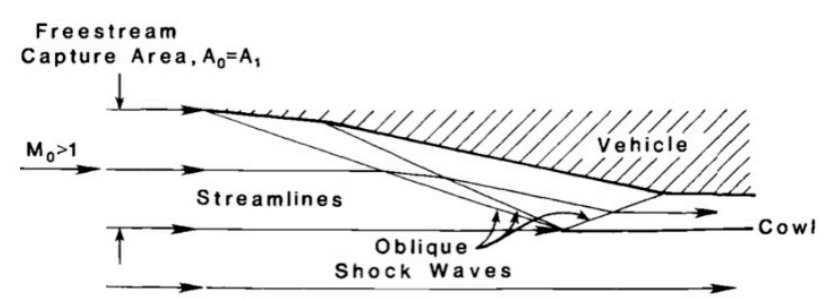

(b)

Figure 2. (a) External compression system and (b) combined external and internal compression system.

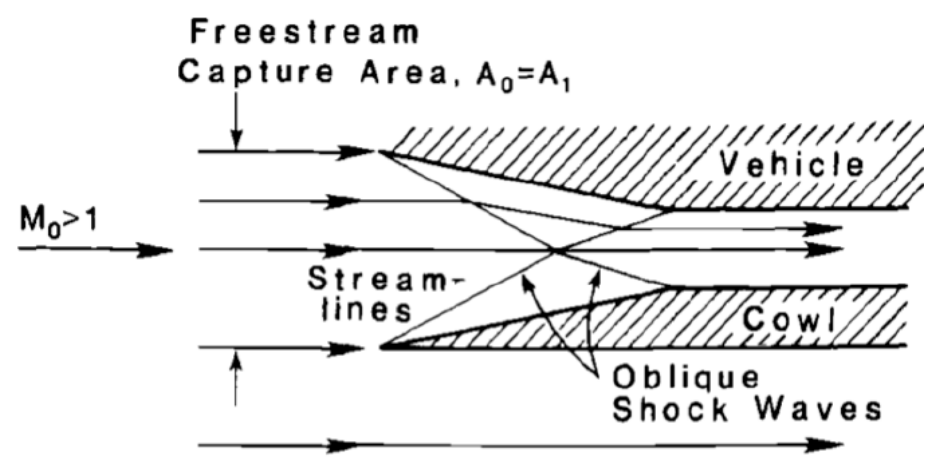

Figure 3. Symmetrical internal compression system.

The inlet is most efficient when the cowl has $100 \%$ flow mass capture because spillage induces spillage drag. For a scramjet, the angle of the external cowl relative to the freestream flow is usually very small in order to minimise external drag. An important aspect in terms of design is to reduce the inlet length until the shock wave criteria are met, with the purpose of reducing the weight of the aircraft, which affects the fuel efficiency and consequently the maximum attainable speed and flight range.

Research conducted by Smart et al. [6] shows that a compression ratio of between 50 to 80 by a scramjet inlet is adequate for flight between Mach 6 and Mach 12 in terms of the highest overall efficiency obtainable. Furthermore, his main observations of scramjet compression systems included (a) most inlets are designed to operate at a range of Mach numbers; (b) not many involve variable geometry due to their shear complexity; (c) boundary layer bleed is not involved and (d) the geometry and compressibility of the inlet governs the design and configuration of the rest of the scramjet engine.

Figure 4 displays the overall efficiency achieved by a research scramjet, at different pressure ratios between the isolator and the freestream $\left(P_{3} / P_{0}\right)$, which is also known as the 'compression ratio' [5]. As it can be seen the overall cycle efficiency initially increases with rising compression ratios for all Mach numbers, however after a pressure ratio of 50 to 80 the overall cycle efficiency begins to decrease again, thus it is not necessary to further increase the compression ratio. It can also be noticed that the overall efficiency decreases with increasing Mach numbers due to the greater viscous losses and increase in shock wave strength. The flow was decelerated to speeds of between Mach 2 to 3 as it enters the combustion chamber. 


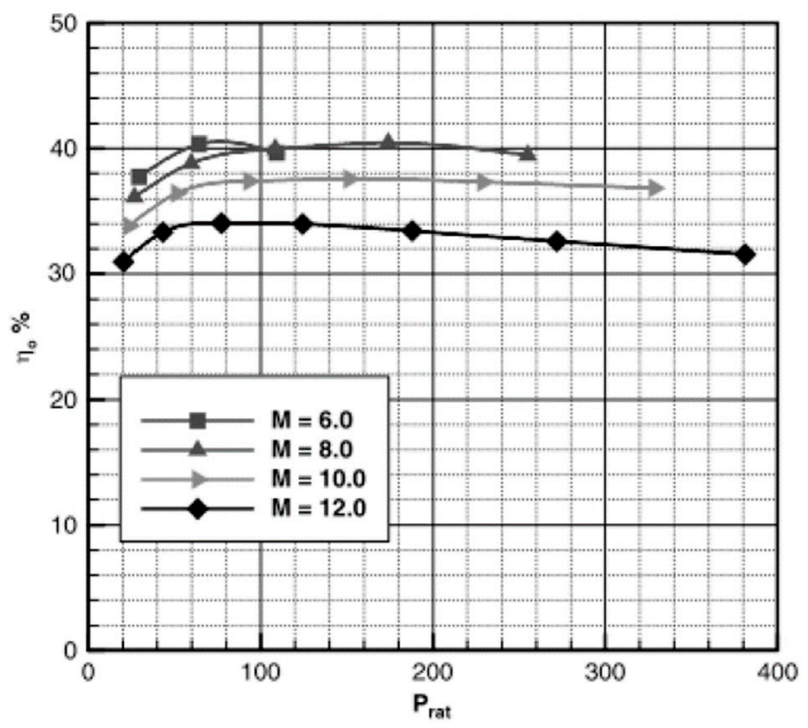

Figure 4. Overall scramjet efficiency at different pressure ratios and Mach number.

The kinetic energy efficiency can be used to quantify the performance of the compression system and usually for simplification the equation can be assumed to be an adiabatic process, which can be seen in Equation (1):

$$
\eta_{K E_{A D}}=\frac{h_{t 0}-h_{2}^{\prime}}{h_{t 0}-h_{0}}
$$

where $\eta_{K E, A D}$ is the adiabatic kinetic energy efficiency, $h_{t 0}$ is the stagnation enthalpy, $h_{2}^{\prime}$ is the isentropic enthalpy at the isolator and $h_{0}$ is the enthalpy. However, the relation does not take heat loss to the vehicle's structure into account.

This relationship is then transformed into a empirical correlation (Equation (2)) developed by Waltrup et al. [7], which is accurate up to a flight speed of Mach 8:

$$
\eta_{K E_{A D}}=1-0.4\left\{1-\frac{M_{2}}{M_{0}}\right\}^{2}
$$

where $\frac{M_{2}}{M_{0}}$ is the ratio of the flow Mach number after passing through the final oblique shock wave and at freestream. Smart [8] has modified the equation for flight speeds greater than Mach 8 (Equation (3)):

$$
\eta_{K E_{A D}}=1-\left(\frac{9}{M_{0}}\right)^{0.7}\left[0.018\left\{1-\frac{M_{2}}{M_{0}}\right\}+0.12\left\{1-\frac{M_{2}}{M_{0}}\right\}^{4}\right]
$$

\subsection{Isolator}

The isolator is a short duct between the inlet and combustion chamber, its name originates from its purpose which is to 'isolate' the oncoming flow and prevent interaction of the combustor and inlet, in order to mitigate flow perturbations caused by the combustion process. These can propagate upstream and affect the operation of the inlet [9]. Furthermore, it contains the shock trains, which are unavoidable 'back-ground waves' encountered in supersonic pressure-gain flows restricted in a duct, with the isolator preventing interaction of the combustor and inlet, else the heat from the combustion can propagate upstream and significantly affect the operation of the inlet [10].

Equation (4) relates the temperature at the combustor entrance $\left(T_{3}\right)$ to the freestream temperature $\left(T_{0}\right)[2]:$

$$
\psi=\frac{T_{3}}{T_{0}}
$$


The ratio of the combustor entrance and freestream entrance areas can be related using Equation (5), this relationship is formed on the basis of the conservation of mass [2]:

$$
\frac{A_{3}}{A_{0}}=\psi \frac{P_{0}}{P_{3}} \frac{u_{0}}{u_{3}}
$$

The inlet stagnation temperature which is constant across a shock wave can be related using Equation (6) [2]:

$$
T_{t}=T_{0}\left(1+\frac{\gamma_{c}-1}{2} M_{0}^{2}\right)=T_{3}\left(1+\frac{\gamma_{c}-1}{2} M_{3}^{2}\right)
$$

Using the above equation the Mach number at the combustion chamber entrance (station 3) can be related to the Mach number at the lip (station 0) during hypersonic flight by Equation (7) [2]:

$$
\frac{M_{3}}{M_{0}}=\sqrt{\frac{T_{0}}{T_{3}}}
$$

\subsection{Combustion Section}

The combustion chamber of a scramjet is where the combustion process ensues, here fuel is injected by the fuel injectors at high velocity into the stream of the oncoming flow, which is delivered at a very high temperature and pressure thus allowing the fuel to combust without the need for burners. Early scramjet research focused on fuel being injected from the walls as opposed to struts at the centre of the engine because struts detrimentally affect the flow path streamlines. More recent research has led to the use of strut injectors since without them, fuel must be injected circumferentially, at higher speeds for better mixing. Scramjets can use either hydrogen or hydrocarbon fuel; hydrogen is a more suitable choice because it has a much higher Lower Heating Value (LHV), for example, hydrogen has a LHV of 119,600 kJ/kg, whereas, Jet Propellant 8 (JP-8) has a LHV of only 43,190 kJ/kg. The resulting exhaust mixture is expelled to the expansion system [11].

\subsection{Expansion Section}

Burnt fuel mixture delivered by the combustion chamber is expanded by the nozzle, during this process energy is extracted from the exhaust mixture as it loses pressure and temperature. Thrust is generated by expelling the exhaust mixture at a higher speed than the freestream velocity. Ideally the pressure at the nozzle exit should be equal to the ambient pressure of the atmosphere at altitude so that the exhaust gases can perfectly expand [12].

Hypersonic vehicles are usually designed to have a large nozzle pressure ratio, thus the nozzle dimensions are long and can have internal and external sections. The reason why a hypersonic vehicle uses the aft as an external expansion surface is because if it only used an internal nozzle then it would be required to be very long (longer than the entire vehicle) in order to generate enough thrust for the vehicle to be propelled to such high speed flight. Bearing in mind, using the vehicle's aft can create lift and pitch moments, which can increase the complexity of the nozzle design as well as integration with the aircraft [13].

Shock diamonds are formed after the exhaust mixture exits the nozzle and it has a somewhat similar structure to that of the shock train in the inlet isolator. The difference is that there is greater expansion because the pressure of the atmosphere is significantly less than in the confined duct. The boundary of the shock diamond is confined by the free jet flow; within this boundary are repeating patterns of oblique shock waves and expansion fans interaction, which continues until the energy of the exhaust gases is dissipated into the atmosphere. 


\subsection{Integration of Engines into Vehicle}

Figure 5 displays the NASA's X-43A vehicle, it is currently the fastest unmanned vehicle to fly with an air-breathing engine, having achieved a flight speed of Mach 9.6. The scramjet it uses is integrated into the vehicle and the forebody is used as an external compression surface. The whole engine is located roughly in the middle of the vehicle and the aft is used at the external expansion surfaces [14].

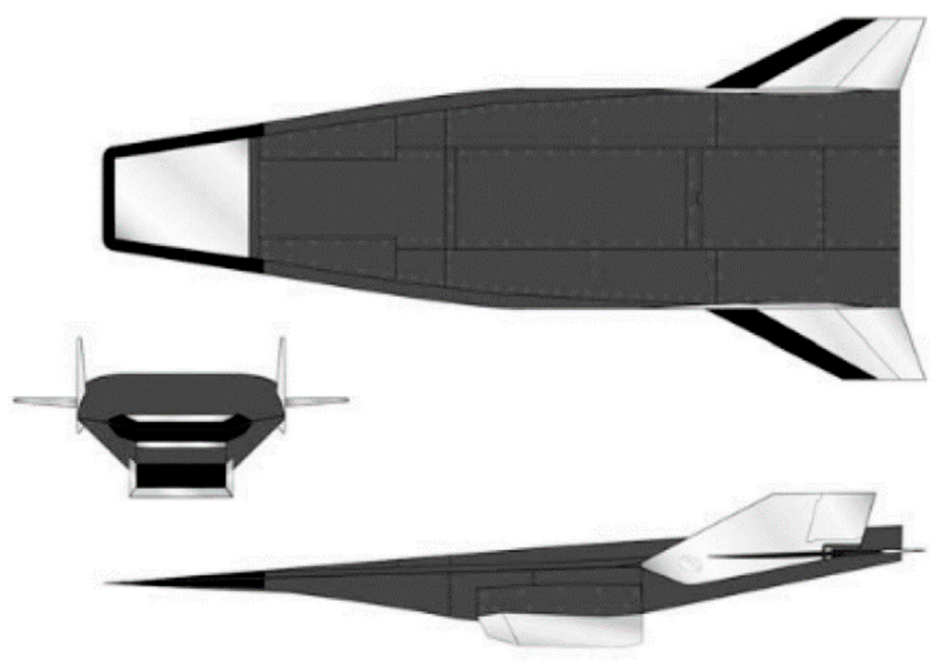

Figure 5. NASA's X-43A vehicle.

There are several reasons why scramjet engines are integrated as part of the vehicle, they are:

- To capture the needed air mass using the forebody under the vehicle as an external compression surface.

- The nozzle required to expand the burnt fuel-air mixture would be very large compared to the original freestream capture area in order to produce sufficient thrust, thus the aft under the vehicle is used as the external expansion surface.

- External self-contained engine would be subjected to huge amount of drag during supersonic and hypersonic speed flights.

Since the vehicle must be propelled from rest on the ground to the hypersonic cruise speeds at high altitude, the best solution is to integrate the turbojet engines into the ramjet and scramjet engines in an over-under (as seen in Figure 6) or wrap-around configuration so that the vehicle is not subjected to immense drag, which can be expected if they were to be attached externally [15].

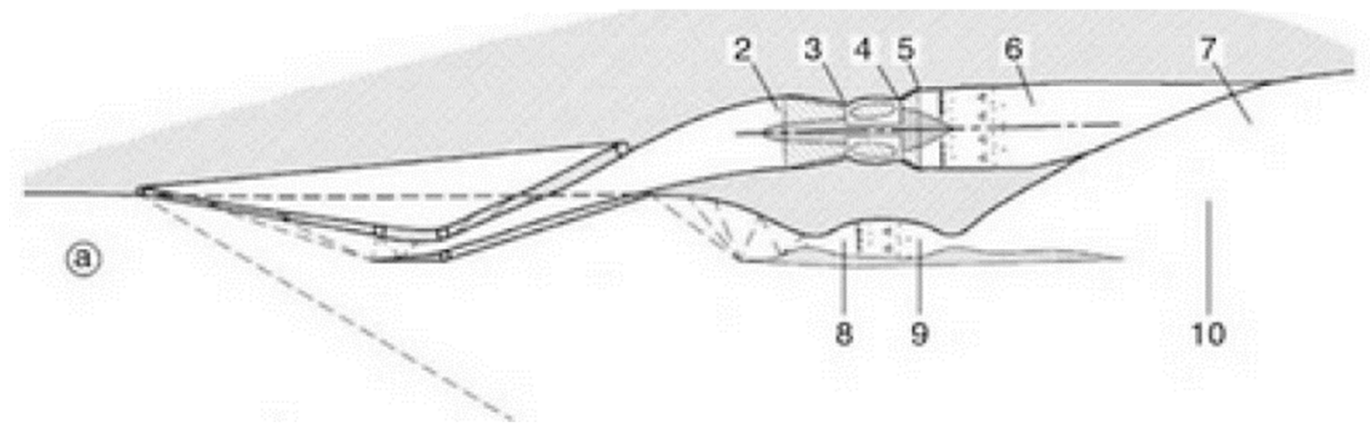

Figure 6. Over-under configuration of a turbojet and ramjet engine. 


\subsection{2-D Compression System Designs}

2-D analysis approach using empirical formulas and 2-D analytical tools allows a basic understanding of the oblique shock waves propagation through the inlet and isolator when varying the number of ramp and deflection angles. The isolator-capture area ratio $\left(A_{3} / A_{0}\right)$ was calculated for each ramp at different flight Mach numbers, however when implemented as the height equivalent on the 2-D simulations, shock structure would not be visible at any Mach number. Therefore, it was decided that spending a lot of time optimising the geometry for basic investigation into the number of ramps and deflection angle would be too time consuming for initial 2-D simulations that may not even be used as the final design. However, for the finalised inlet the area ratio is planned to be used as it is derived whilst taking conservation of mass into account.

\section{Concept Aircraft Specification}

The hypersonic hybrid propulsion concept is based around a self-sustained concept aircraft required to achieve a full commercial-style flight profile for passenger transportation. An example outline of the desired profile is given in Table 1 [5]. In order to remain self-sustained, the profile is attained by the combined operation of a turbojet, ramjet, and scramjet propulsion system.

A feasible combination of a dual-mode ramjet-scramjet is given by Figure 7, such that during high-altitude scramjet flight the ramjet inlets are sealed to prevent excessive drag induced by shockwaves on the ramjet forebody.

Table 1. Concept aircraft target flight profile.

\begin{tabular}{|c|c|c|c|c|c|c|}
\hline Phase & Description & Altitude (ft) & Mach & Turbojet & Ramjet & Scramjet \\
\hline 1 & $\begin{array}{c}\text { Take-off and Initial } \\
\text { Climb }\end{array}$ & $0-1500$ & 0 to 1 & & & \\
\hline 2 & Climb 1 & $1500-40,000$ & 1 to 2 & & & \\
\hline 3 & Climb 2 & $40,000-60,000$ & 2 to 4 & & & \\
\hline 4 & Climb 3 & $60,000-100,000$ & 4 to 7 & & & \\
\hline \multirow[t]{2}{*}{5} & Cruise & 100,000 & 8 & & & \\
\hline & Single Operation & & Dual Operation & & No & tion \\
\hline
\end{tabular}

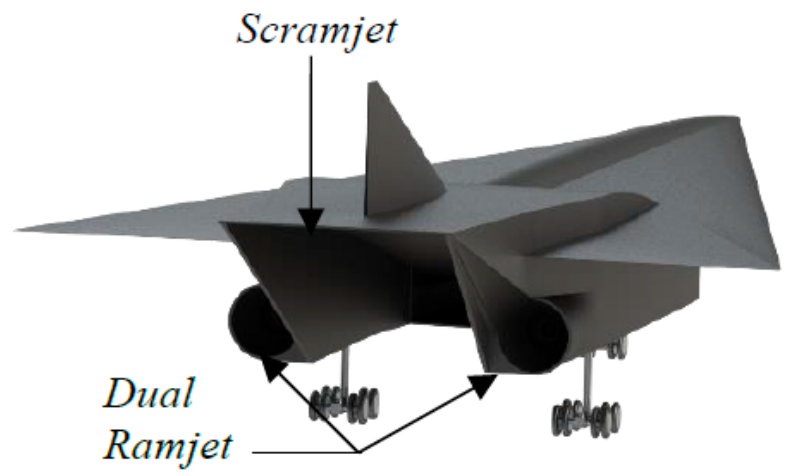

Figure 7. Concept hypersonic aircraft.

The requirement from this aircraft was for sustained Mach 8 cruise flight for a substantial part of the flight envelope with the ramjets assisting during phases 2 and 3 of the flight envelope (Table 1). The concept paper as well as it combustion characteristics have been detailed in a previous publications [16,17]. 


\section{Theoretical Performance of Initial Designs}

A 2-D approach allows a basic understanding of the oblique shock wave propagation through the inlet and isolator when varying the number of ramp and deflection angles. The isolator-capture area ratio $\left(A_{3} / A_{0}\right)$ was calculated for each ramp at different flight Mach numbers.

\subsection{Two Ramp Inlet}

Figure 8 displays the schematic of a two ramp external compression system with deflection angles for the first and second ramp of $9^{\circ}$ and $11.5^{\circ}$, respectively. The length of the flat surface underneath the vehicle's forebody and the horizontal length of the ramps was set to $35 \mathrm{~m}$ to allow the development of the boundary layer. However, the exact distance of the flat surface does not make much of a difference as long as the flow is parallel the horizontal plane.

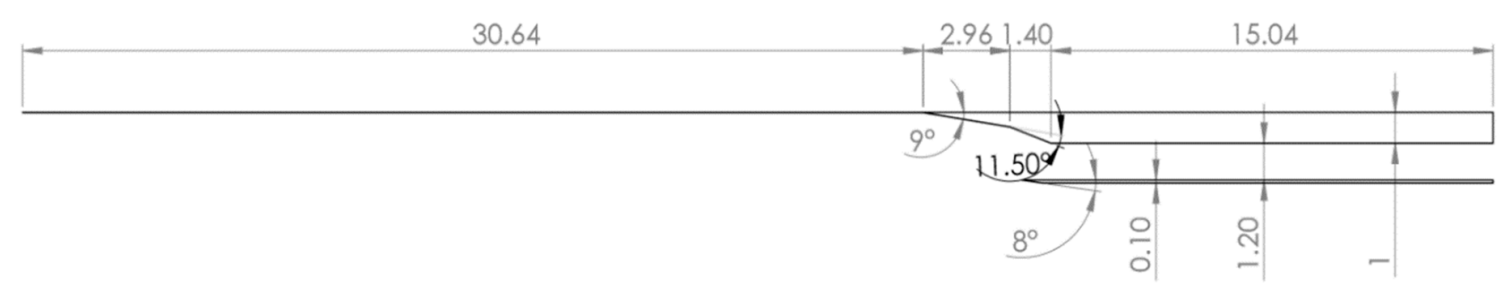

Figure 8. Two ramp inlet schematic (dimensions in metres).

From the theory of oblique shock waves (Section 2), calculations were done to identify the theoretical performance of a scramjet inlet; Table 2 presents some of the important values such as compression and pressure recovery achieved from the two ramp system.

Table 2. Theoretical calculations for two ramp inlet.

\begin{tabular}{ccccccc}
\hline M1 & M2 & M3 & $\begin{array}{c}\text { Compression Ratio } \\
\text { (Prat) }\end{array}$ & $\begin{array}{c}\text { Pressure Recovery } \\
\text { (Prec) }\end{array}$ & $\begin{array}{c}\text { Temperature } \\
\text { Increase }(\varphi)\end{array}$ & $\begin{array}{c}\text { Adiabatic Efficiency, } \\
\eta_{K E, A D}\end{array}$ \\
\hline 4.00 & 3.36 & 2.71 & 5.65 & 0.88 & 1.70 & 0.9867 \\
4.50 & 3.74 & 2.99 & 6.73 & 0.84 & 1.81 & 0.9874 \\
5.00 & 4.10 & 3.25 & 7.98 & 0.80 & 1.93 & 0.9878 \\
5.50 & 4.45 & 3.49 & 9.39 & 0.76 & 2.06 & 0.9882 \\
6.00 & 4.78 & 3.71 & 11.00 & 0.71 & 2.33 & 0.9884 \\
6.50 & 5.10 & 3.91 & 12.78 & 0.67 & 2.47 & 0.9887 \\
7.00 & 5.41 & 4.11 & 14.80 & 0.62 & 2.68 & 0.9889 \\
7.50 & 5.70 & 4.27 & 17.00 & 0.58 & 2.80 & 0.9890 \\
8.00 & 5.98 & 5.45 & 28.42 & & 0.9920 \\
\hline
\end{tabular}

As it can be seen with increasing Mach number of the incoming freestream flow (M1) the flow downstream of the oblique shock (M1) also stays at a higher Mach number. Moreover, with increasing M1 the compression also increases along with static temperature. However, even at a flight speed of Mach 8 it does not reach the necessary levels of compression, which should be between 50 and 100 [6]. The pressure recovery becomes worse with increasing Mach number, therefore more oblique shocks will be needed to have a compromise between compression achieved and pressure recovery.

\subsection{Three Ramp Inlet}

Figure 9 depicts the schematic of a three ramp inlet design with deflection angles; $\theta 1=9.5^{\circ}$, $\theta 2=9.5^{\circ}$ and $\theta 3=9.5^{\circ}$, having the same deflection angle for all ramps allows for the best pressure recovery. 


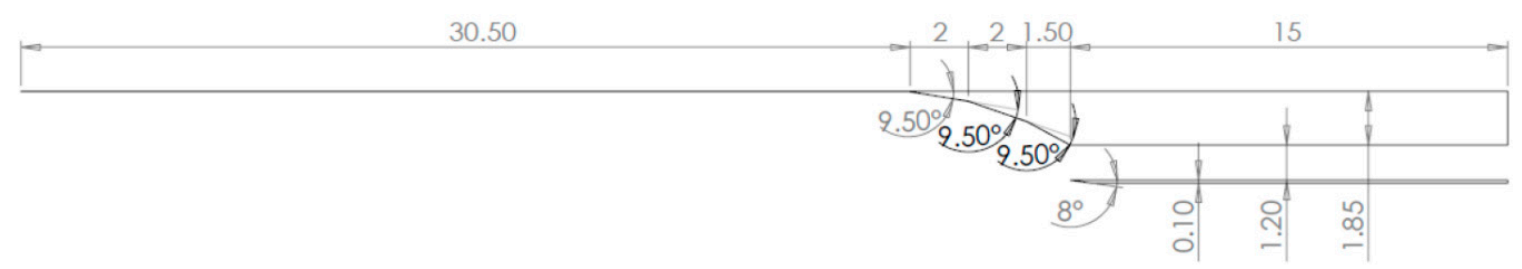

Figure 9. Three ramp inlet schematic (dimensions in metres).

Table 3 presents the theoretical calculations of the Mach number downstream, compression ratio, pressure recovery, static temperature increase and adiabatic efficiency at a range of freestream flow speeds. As it can be seen at Mach 8 the flow should decelerate to Mach 3.788 after passing through the final oblique shock wave, which reaches compression ratio and pressure recovery of 44.54 and 0.52 , respectively. The compression ratio is still not within the target range and the pressure recovery is relatively low due to the high angles of deflection.

Table 3. Theoretical calculations for three ramp inlet.

\begin{tabular}{cccccccc}
\hline M1 & M2 & M3 & M4 & $\begin{array}{c}\text { Compression Ratio } \\
\text { (Prat) }\end{array}$ & $\begin{array}{c}\text { Pressure Recovery } \\
\text { (Prec) }\end{array}$ & $\begin{array}{c}\text { Temperature } \\
\text { Increase }(\varphi)\end{array}$ & $\begin{array}{c}\text { Adiabatic } \\
\text { Efficiency, } \eta_{K E, A D}\end{array}$ \\
\hline 4.00 & 3.32 & 2.79 & 2.36 & 9.71 & 0.87 & 1.99 & 0.9836 \\
4.50 & 3.70 & 3.09 & 2.60 & 12.12 & 0.83 & 2.15 & 0.9846 \\
5.00 & 4.05 & 3.36 & 2.82 & 14.94 & 0.79 & 2.31 & 0.9852 \\
5.50 & 4.39 & 3.61 & 3.02 & 18.35 & 0.75 & 2.68 & 0.9858 \\
6.00 & 4.71 & 3.84 & 3.20 & 22.25 & 0.70 & 2.89 & 0.9862 \\
6.50 & 5.03 & 4.07 & 3.37 & 26.82 & 0.66 & 3.10 & 0.9866 \\
7.00 & 5.32 & 4.27 & 3.52 & 32.01 & 0.61 & 3.33 & 0.9869 \\
7.50 & 5.60 & 4.46 & 3.66 & 37.88 & 0.56 & 3.57 & 0.9872 \\
8.00 & 5.87 & 4.63 & 3.79 & 44.54 & 0.52 & 0.9875 \\
\hline
\end{tabular}

\subsection{Four Ramp Inlet}

Figure 10 exhibits the schematic of a four ramp inlet design with deflection angles; $\theta 1=8^{\circ}, \theta 2=8^{\circ}$, $\theta 3=8^{\circ}$ and $\theta 4=4.5^{\circ}$, these values were selected so as to compare the difference in performance whilst having the same total deflection angle as the three ramped inlet.

Table 4 shows the calculated properties. At Mach 8 the compression ratio achieved is 47.05 , the pressure recovery is $62.5 \%$ and the temperature increase ratio is 3.489 . The compression ratio and stagnation pressure recovery achieved is better than the three ramp inlet with the total deflection (three ramp inlet has Prat $=44.54$ and Prec $=52 \%$ ); however the compression ratio is less than the target ratio of 50 , therefore it needs to be modified.

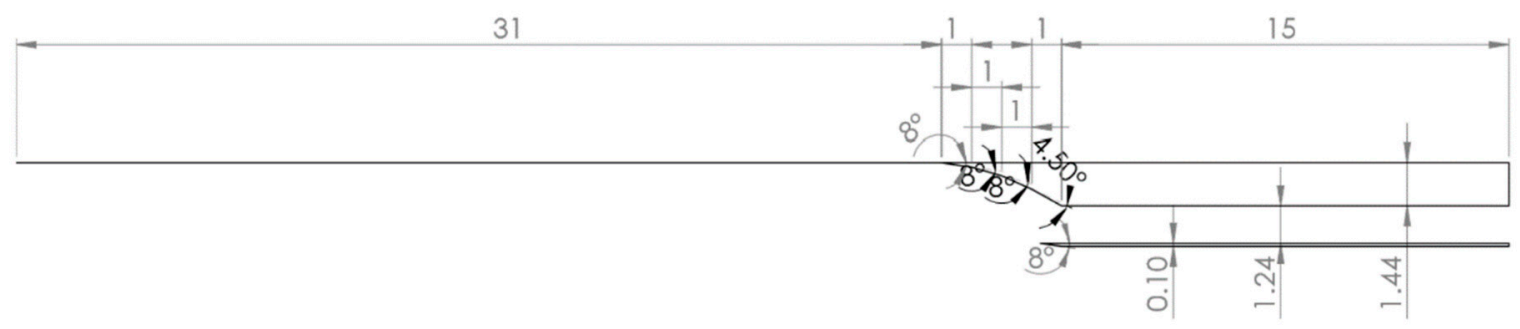

Figure 10. Four ramp inlet schematic (dimensions in metres). 
Table 4. Theoretical calculations for four ramp inlet.

\begin{tabular}{|c|c|c|c|c|c|c|c|c|}
\hline M1 & M2 & M3 & M4 & M5 & $\begin{array}{l}\text { Compression } \\
\text { Ratio (Prat) }\end{array}$ & $\begin{array}{c}\text { Pressure } \\
\text { Recovery (Prec) }\end{array}$ & $\begin{array}{c}\text { Temperature } \\
\text { Increase }(\varphi)\end{array}$ & $\begin{array}{c}\text { Adiabatic } \\
\text { Efficiency, } \eta_{K E, A D}\end{array}$ \\
\hline 4.00 & 3.427 & 2.963 & 2.570 & 2.431 & 9.791 & 0.911 & 1.971 & 0.98425 \\
\hline 4.50 & 3.817 & 3.279 & 2.839 & 2.694 & 12.243 & 0.884 & 2.120 & 0.98520 \\
\hline 5.00 & 4.198 & 3.582 & 3.088 & 2.934 & 15.222 & 0.853 & 2.334 & 0.98590 \\
\hline 5.50 & 4.565 & 3.871 & 3.324 & 3.163 & 18.783 & 0.818 & 2.448 & 0.98649 \\
\hline 6.00 & 4.917 & 4.135 & 3.534 & 3.366 & 22.925 & 0.781 & 2.625 & 0.98692 \\
\hline 6.50 & 5.254 & 4.385 & 3.729 & 3.556 & 27.778 & 0.742 & 2.813 & 0.98729 \\
\hline 7.00 & 5.577 & 4.619 & 3.908 & 3.728 & 33.337 & 0.704 & 3.010 & 0.98760 \\
\hline 7.50 & 5.897 & 4.841 & 4.077 & 3.889 & 39.810 & 0.665 & 3.219 & 0.98788 \\
\hline 8.00 & 5.194 & 5.048 & 4.233 & 4.039 & 47.054 & 0.625 & 3.435 & 0.98813 \\
\hline
\end{tabular}

\section{Computational Fluid Dynamics (CFD) Setup Validation}

Work done by Smayda et al. [4] was used as a means of validating the CFD setup on ANSYS Fluent (Canonsburg, PA, USA), in addition to the data comparison between theoretical and CFD results. Since it is difficult to find a complete list of CFD setup for hypersonic flow problems, further research papers and tutorials were used $[1,18,19]$. Even then, some settings were deduced by changing one parameter and observing the convergence residuals as well as shock structure at the ramps and isolator.

The accuracy of the solution obtained from CFD simulations depends on various parameters, such as, size of the control volume, meshing properties, boundary definition, orientation of boundary and discretization method, as well as most importantly the solving method [20]. A density-based solver is used in supersonic and hypersonic flight conditions because air is compressible at high speed flight, therefore using pressure-based simulation would not produce accurate results. Steady flow was chosen as the point of interest is the identification of oblique shock wave propagation and average fluid properties of the flow, and not the development of the flow over a period of time.

2-D simulation of turbulent flow was conducted using the Shear Stress Transport (SST) k-omega compressible turbulent formulations, which is a form of the Reynolds Average Navier-Stokes (RANS) approach. RANS involves solving equations in their ensemble or time-averaged form. The averaging is done on a large number of the same experiment; therefore, the simulation must run until solution convergence is achieved. Where convergence is usually depicted when the residuals drop by at least 3 orders of magnitude.

In order to provide an accurate representation of hypersonic flight, pressure-farfield was used for the input of flow into and out of the computational domain. The boundary and initial conditions were selected for cruise altitude of 100,000 ft for all Mach numbers, this would allow for simplification and easier performance comparison. The structure of the scramjet was set at the wall which obeyed to no-slip condition thus creating boundary layer profile which would be expected in reality. For the simulations of only the scramjet compression system the exit of the scramjet was established with the boundary conditions of the theoretical calculations in order to represent the backpressure and temperature that would emanate from combustion chamber. Here, the isolator exit gauge pressure and temperature are directly proportional to the exit Mach number.

The Courant number was limited to 0.5 to 2, the Courant dictates the change in time period between each iteration of the solutions. A small Courant number is used in the initial start-up stage of the simulation as the changes in the solution are highly non-linear. The Courant number increases gradually in order to keep the time jump between each experiment relatively small, thus minimising divergence. The setup has allowed convergence to be achieved for all 2-D simulations. 3-D simulations had almost the same setup, however the enclosure is 3-D, and thus the boundary conditions are applied on the faces rather than a line.

The boundary conditions included for a varied Mach number range at absolute, ambient total pressure of $109,000 \mathrm{~Pa}$ and equivalent total temperature of $227.13 \mathrm{~K}$.

Figure 11 displays the static pressure contours of the scramjet designed by Smayda et al. [4]. Here the shock placement and structure can be compared along with the performance in terms of compression achieved (i.e., increase in static pressure). 


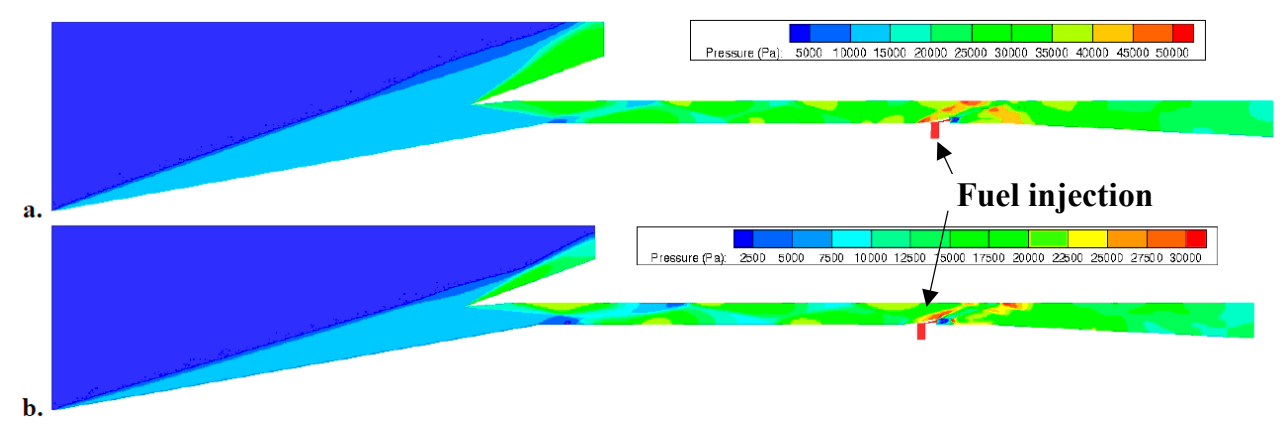

Figure 11. Static pressure contour obtained by Smayda; (a) at Mach 5 and (b) at Mach 7.

Figure 12a displays the CFD results obtained from the most optimum setup on ANSYS Fluent 17.0. The geometry was replicated by measuring the schematic as exact dimensions were not provided. It can be noticed that the oblique shock wave produced at the ramp impinge at roughly the same position as in Figure 11. The slight difference in clarity is due to Smayda's computational domain using 14 million elements [4], whereas the computational domain in Figure 12a uses 190,000 elements which was found to be sufficient while saving on computational cost as used in the overall project study. The use of 190,000 elements was justified by mesh convergence study illustrated below in Figure 12b, which shows that after 190,000 elements, there were no significant change to the results. The results in Figure $12 \mathrm{~b}$ are indicative and derived from the original simulations for the ramjet system, published by Baidya et al. [17], while similar convergence effects were obtained at the higher Mach numbers tested in scramjet-suitable conditions.

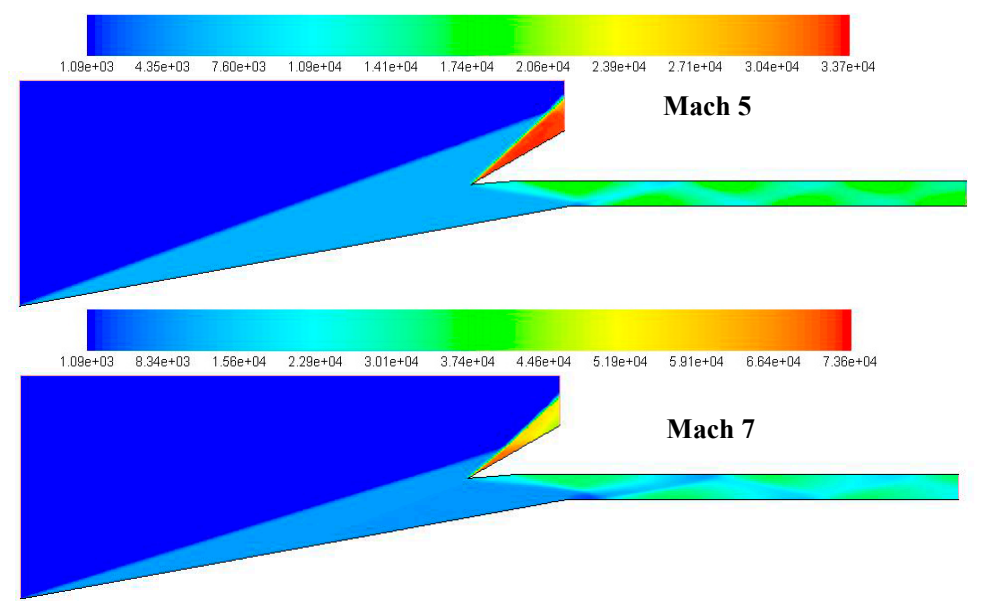

(a)

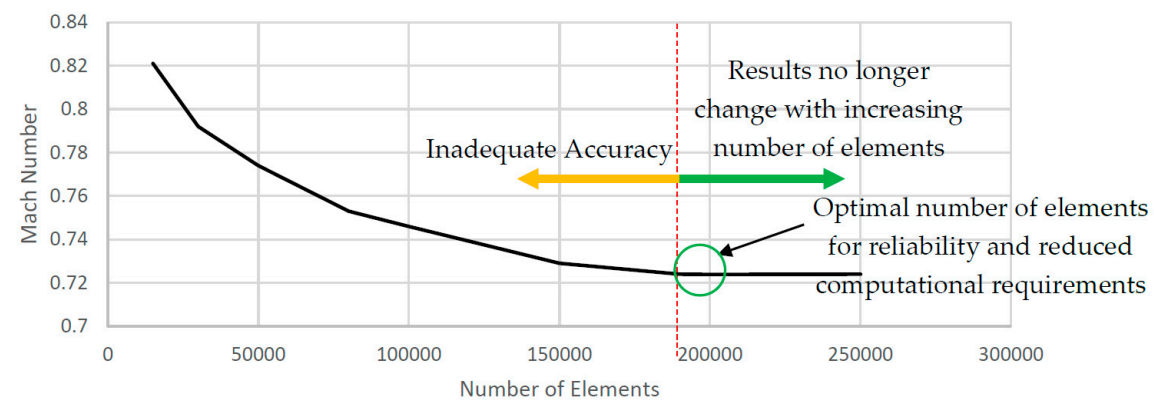

(b)

Figure 12. (a) Static pressure contour obtained in ANSYS Fluent with setup and (b) grid independence associated with the CFD setup. 
Figure 13 displays the static pressure variation along the centre line of the scramjet inlet-isolator of both the CFD results obtained by Smayda et al. [4] and the CFD simulations conducted using the established ANSYS Fluent setup. For Mach 5, the static pressure variation of the validation corresponds well with results obtained in the established CFD; and at Mach 7 the results from the established CFD setup does follow the shape of the validation results to a reasonable level of accuracy for the purposes of this investigation (shock structures match).

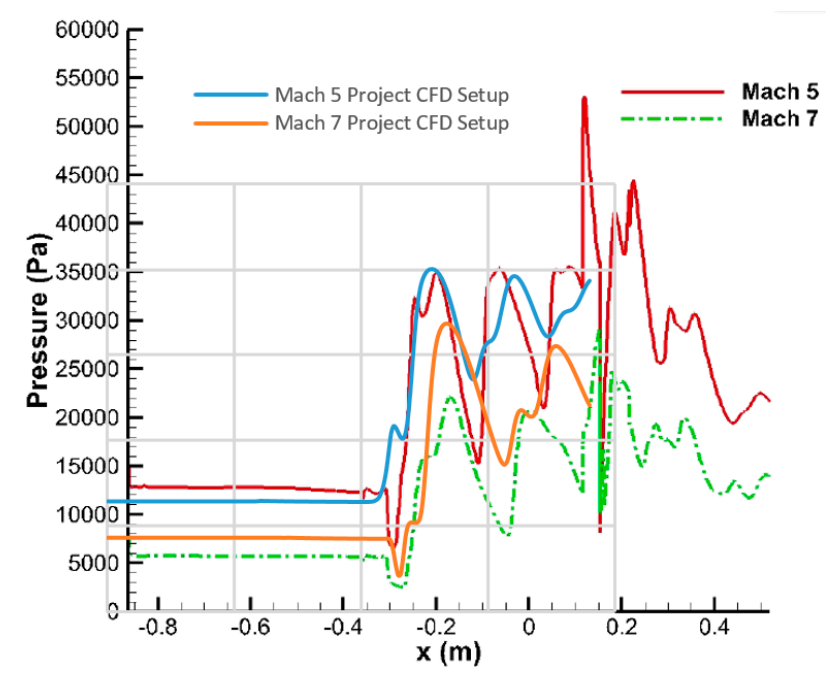

Figure 13. Pressure plot along the centre line of the inlet and isolator.

\subsection{Two Ramp Inlet}

Figure 14 displays the Mach number contour of the two ramp inlet at flight speeds of Mach 5 and Mach 8. For both flows the flow remains attached on the surface of the forebody and the boundary layers are relatively thin compared to the simulation with the bow shock on Figures 4-9. At Mach 5 the boundary layer is thicker at the flat surface underneath the vehicle's forebody and at the ramp, whereas at Mach 8 the boundary layer is thinner at both forebody and at the ramps.

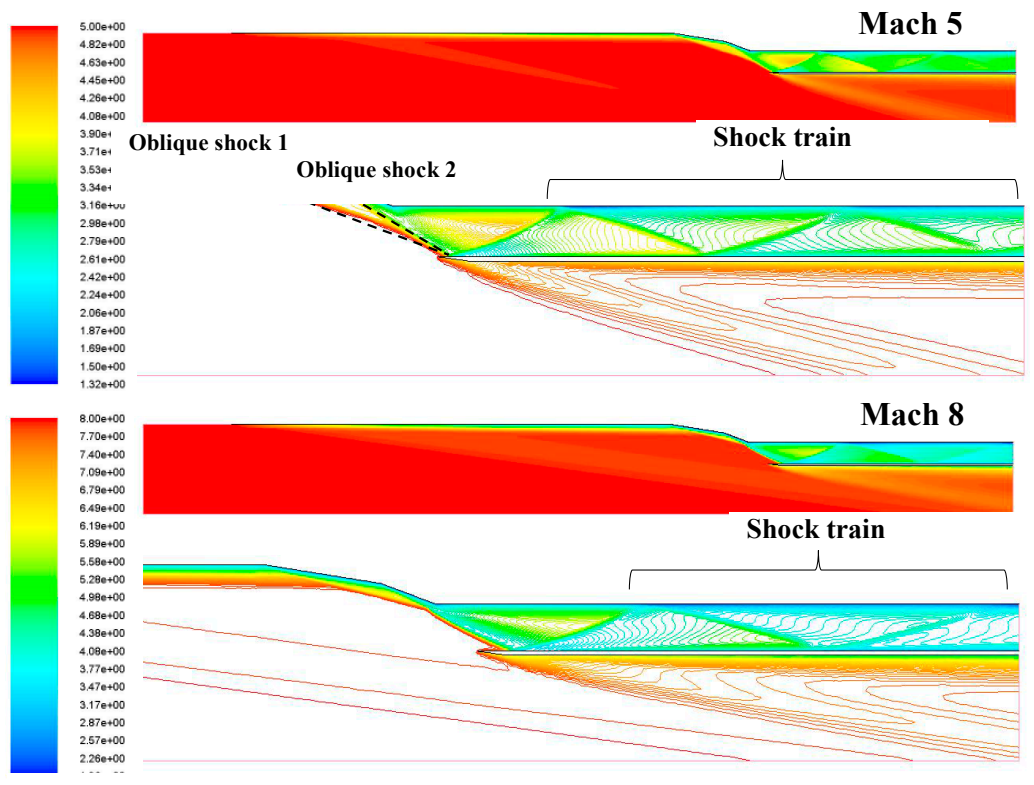

Figure 14. Mach contour of the two ramp inlet at Mach 5 and 8. 
At Mach 5 the two oblique shock waves are visually separable, the impingement occurs at the cowl lip. It can also be noticed that the oblique shock waves are reflected several times inside in the inlet duct but the speed of the flow stays relatively constant at Mach 2.651 throughout the isolator (compared to a theoretical value of Mach 2.707), this allows us to assume that the flow entering the scramjet combustion chamber will be constant since the exact isolator length has not been identified at the time these simulations were conducted. At Mach 8 the individual shock waves impingements are not observed because the flow speed is so quick that shock layer is observed between the surface of the scramjet and the shock waves due to the smaller oblique shock angle. The impingement can be seen to occur slightly behind the cowl lip.

At Mach 8 the flow speed at the isolator was found to be Mach 5.364, compared to Mach 5.447 from the theoretical calculations (difference of 3.1\%). Whereas, at Mach 5 the speed at the isolator was found to be 3.381 compared to the theoretically calculated Mach 3.250, which is a difference of $4.03 \%$. This difference between simulation and theoretical result is quite insignificant as the theoretical calculations assumes a completely adiabatic process.

\subsection{Three Ramp Inlet}

Figure 15 displays the Mach number contour of the three ramp inlet at flight speeds of Mach 5 and Mach 8. As in the two ramp inlet a thinner shock layer can be observed when the freestream speed increases from Mach 5 to Mach 8. Flow separation can be detected during flight at both speeds because either the inlet has not been optimised to fly at either speeds or the ramp angles are too great that it promotes flow separation.

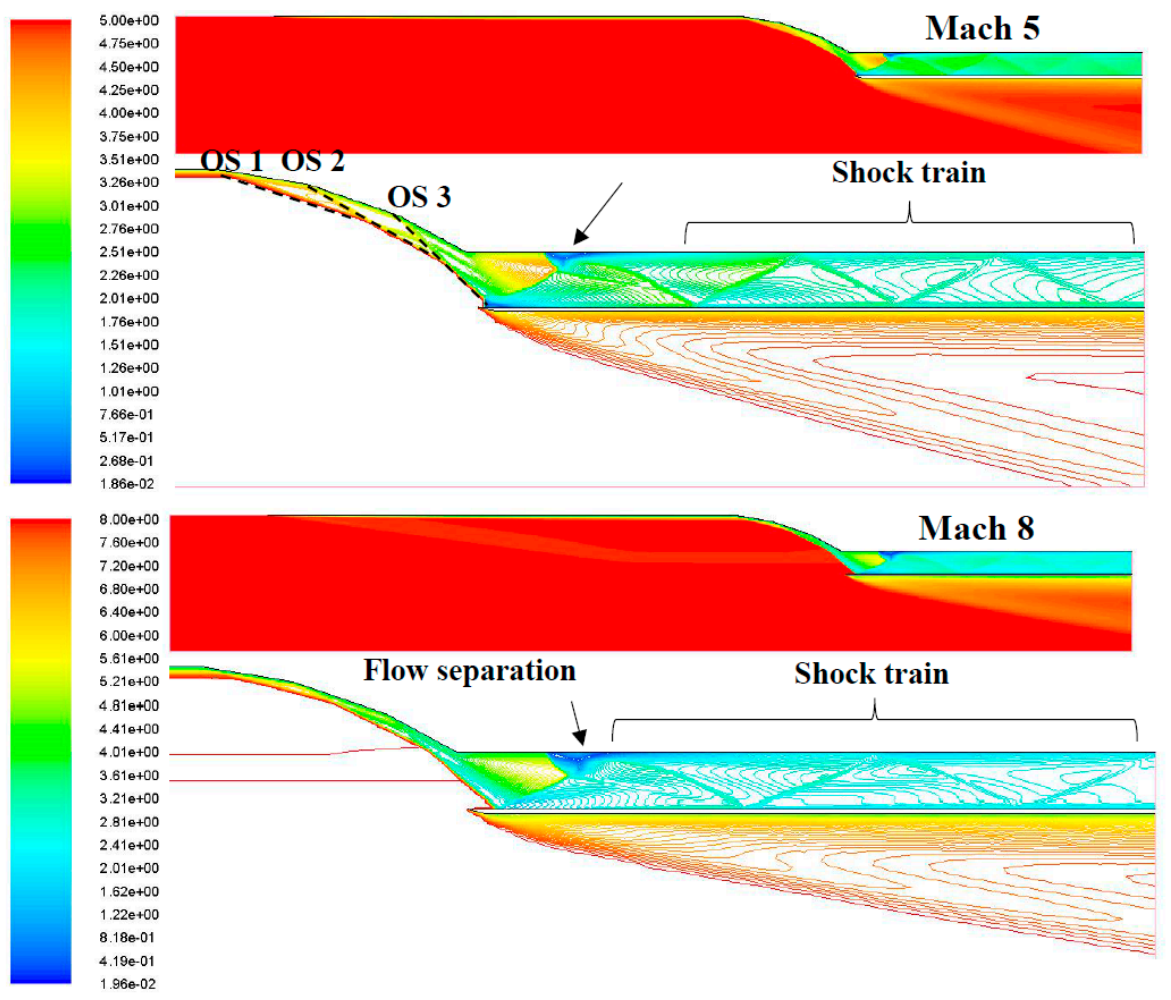

Figure 15. Mach contour of the three ramp inlet at Mach 5 and 8.

It was already identified that the design could not provide the necessary compression through empirical formulas, but the simulation was conducted as a means of presenting and comparing the performance of different ramped inlets in a visual manner. 


\subsection{Four Ramp Inlet}

Figure 16 displays the Mach contour of the initial four ramp inlet. Due to the increase number of ramps shock layer can be observed even at Mach 5, and it is even thinner shock layer for Mach 8. As it can be seen the design works better at Mach 8 since there isn't any significant flow separation. Whereas, there is substantial flow separation at Mach 5 subsequently leads to a non-existent shock train in the isolator; this could potentially result in propagation of flow disturbances caused by the energy release in the combustion chamber, which should be avoided.

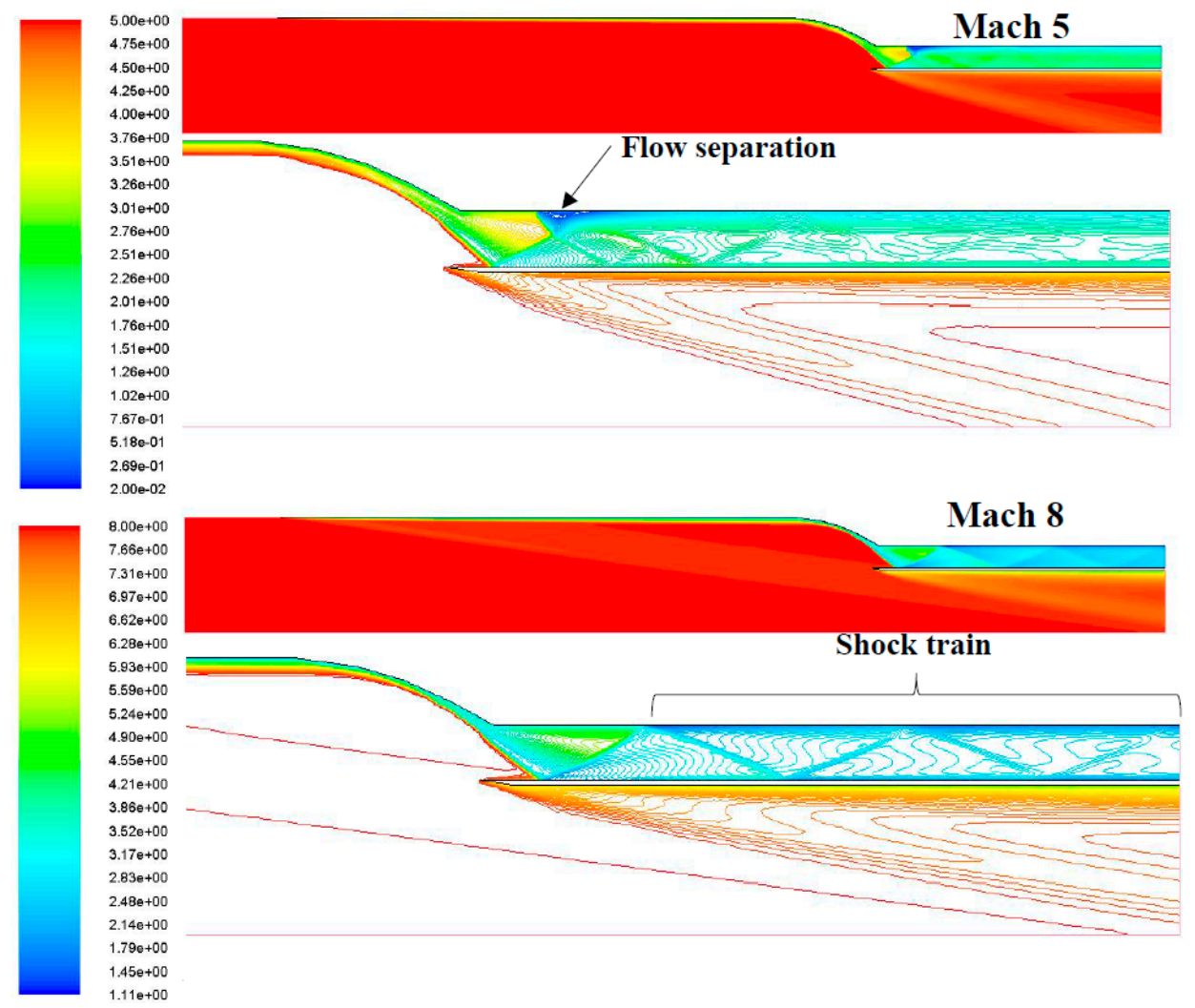

Figure 16. Mach contour of the three ramp inlet at Mach 5 and 8.

\subsection{Comparison of Different Ramped Inlets}

From the calculations using the empirical formulas it was found that two and three ramped inlets which generate two and three oblique shocks, respectively, do not produce the required levels of compression without compromising on the stagnation pressure recovery. The three ramp inlet above does provide 44 times compression however its stagnation pressure recovery is only $52.0 \%$, whereas the four ramped inlet with the same degree of total deflection $\left(28.5^{\circ}\right)$ provides a much greater pressure recovery of $62.5 \%$ as well as compression ratio of 47 . The deflection angle of the three ramped inlet could be increased to achieve higher levels of compression but would lead to even greater loss in stagnation pressure, which is not ideal.

With increasing flight speed the shock layer was found to be thinner and the combined shock waves impinge further downstream from the cowl lip. It was noted that the cowl lip had to be placed relatively forward so that shock waves could impinge within the cowl lip at all stages of flight.

Adding more than four ramps to generate additional oblique shock waves and subsequently better stagnation pressure recovery is possible but it increases the complexity of the geometry. Therefore, it was decided that a four ramp inlet producing four oblique shocks was the best compromise between scramjet inlet performance and geometry complexity. The four ramp inlet had to be modified in order to obtain necessary levels of compression. 


\subsection{Refinement of the Four Ramp Inlet}

From conducting theoretical calculations and CFD simulations it was deemed that four ramp system was the best compromise in order to reach anywhere near the compression ratio needed by the scramjet engine whilst having adequate performance. Taking the four ramp design presented in Section 4.3 as an initial foundation, the deflection angles was increased gradually until a compression ratio of 50 was achieved, which is the in the lower range of compression ratios needed as discussed in Section 2.

Using empirical equations and this was found when the ramp deflections are $\theta 1=8^{\circ}, \theta 2=8^{\circ}$, $\theta 3=8^{\circ}$ and $\theta 4=5.2^{\circ}$. The first three ramps have the same deflection angle so that the best pressure recovery is achieved. The final deflection angle is less than the first three to lessen the amount of influence of the expansion fan after the sudden flow area increase after the final ramp and into the isolator.

Table 5 displays the theoretical calculations; at the cruise flight speed of Mach 8 the scramjet inlet should theoretically compress the flow just over 50 times and it should as decelerate the flow to Mach 3.766 downstream of the final oblique shock wave.

Table 5. Theoretical calculations for the refined four ramp inlet.

\begin{tabular}{|c|c|c|c|c|c|c|c|c|}
\hline M1 & M2 & M3 & M4 & M5 & $\begin{array}{l}\text { Compression } \\
\text { Ratio (Prat) }\end{array}$ & $\begin{array}{c}\text { Pressure } \\
\text { Recovery (Prec) }\end{array}$ & $\begin{array}{l}\text { Temperature } \\
\text { Increase }(\varphi)\end{array}$ & $\begin{array}{c}\text { Adiabatic } \\
\text { Efficiency, } \eta_{K E, A D}\end{array}$ \\
\hline 4.00 & 3.43 & 2.96 & 2.57 & 2.43 & 9.79 & 0.911 & 1.971 & 0.9843 \\
\hline 4.50 & 3.82 & 3.28 & 2.84 & 2.69 & 12.24 & 0.884 & 2.120 & 0.9852 \\
\hline 5.00 & 4.20 & 3.58 & 3.09 & 2.93 & 15.22 & 0.853 & 2.334 & 0.9859 \\
\hline 5.50 & 4.57 & 3.87 & 3.32 & 3.16 & 18.78 & 0.818 & 2.448 & 0.9865 \\
\hline 6.00 & 4.92 & 4.14 & 3.53 & 3.37 & 22.93 & 0.781 & 2.625 & 0.9869 \\
\hline 6.50 & 5.25 & 4.39 & 3.73 & 3.56 & 27.78 & 0.742 & 2.813 & 0.9873 \\
\hline 7.00 & 5.56 & 4.62 & 3.91 & 3.73 & 33.38 & 0.704 & 3.010 & 0.9876 \\
\hline 7.50 & 5.90 & 4.84 & 4.08 & 3.89 & 39.81 & 0.665 & 3.219 & 0.9879 \\
\hline 8.00 & 6.19 & 5.05 & 4.23 & 4.04 & 47.05 & 0.625 & 3.435 & 0.9881 \\
\hline
\end{tabular}

Figure 17 displays the ideal propagation of the oblique shockwaves for the proposed design; after the final ramp an expansion fan is expected to the sudden divergence in area. From observation of the CFD simulations the oblique shock waves are likely to be curved and almost on top of each other, forming a shock layer because of the speed at which the flow is being directed into the inlet.

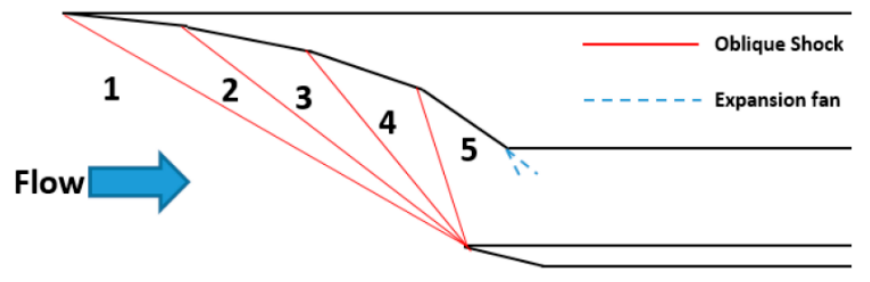

Figure 17. Ideal oblique shock propagation for the four ramp inlet.

\subsection{Comparison of Theoretical Performance between Inlet Designs}

Figure 18 displays the Mach number at the isolator entrance at different flight Mach numbers for the different inlet designs. The general trend is that the flow Mach number at the isolator increases when the flight Mach increases due to the flow initially having greater kinetic energy. The almost linear trend from Mach 4 to 7 for all inlet designs suggests that the flow losses a similar ratio of kinetic energy no matter how many ramp and deflection angles the inlet has. However, after Mach 7 this trend dissolves, indicated by the steep increase in Mach number for the two ramp inlet.

Figure 19 displays the adiabatic efficiency $\left(\eta_{K E, A D}\right)$ of converting the kinetic energy from the flow into compression for the different inlet designs. The general trend is that the efficiency increases with 
higher compression attained for all inlet designs. As the number of ramp and the deflection angles increases the adiabatic efficiency of the inlet decreases.

The two ramp inlet is the most efficient, however only the four ramp inlet with a deflection angle of $\theta 1=8^{\circ}, \theta 2=8^{\circ}, \theta 3=8^{\circ}$ and $\theta 4=5.2^{\circ}$ achieves the level of compression needed.

Figure 20 displays the comparison of the pressure recovery $\left(\mathrm{P}_{\mathrm{t} 2} / \mathrm{P}_{\mathrm{t} 1}\right)$ and compression ratio $\left(P_{3} / P_{0}\right)$ of the different inlet designs. As it can be noticed having more ramps with lower deflection angles compression achieved does not reach the required levels. The three ramp and the initial four ramp inlet improves the pressure recovery because the deflection angle dictate the flow properties after passing through shock waves, where a higher deflection angle results in lower pressure recovery.

The pressure recovery trend decreases with increasing Mach number for all inlet designs because at higher flow speeds the flow is more abruptly decelerated after passing through an oblique shock wave. The level of compression achieved by the inlet improves with increasing number of ramps because each oblique shock wave generates a specific level of compression (greater than 1). Higher deflection angles result in better compression because the upstream flow has higher amount of kinetic energy, which it can use to turn the flow onto itself with greater momentum. But it can result in poor stagnation pressure recovery and more dangerously, flow detachment. Therefore, a compromise between compression ratio and stagnation pressure recover is necessary as discussed in Section 2.4.

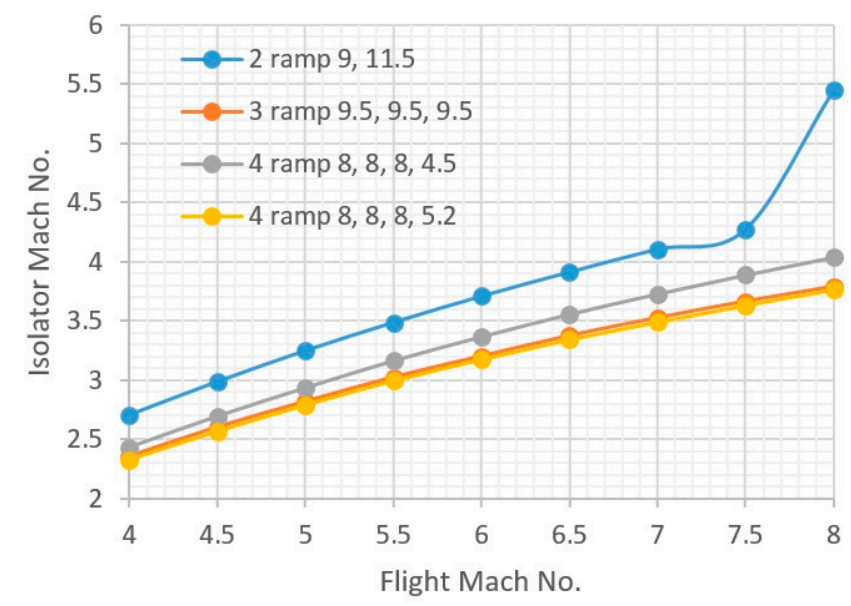

Figure 18. Mach number downstream of final shock wave for different starting Mach number.

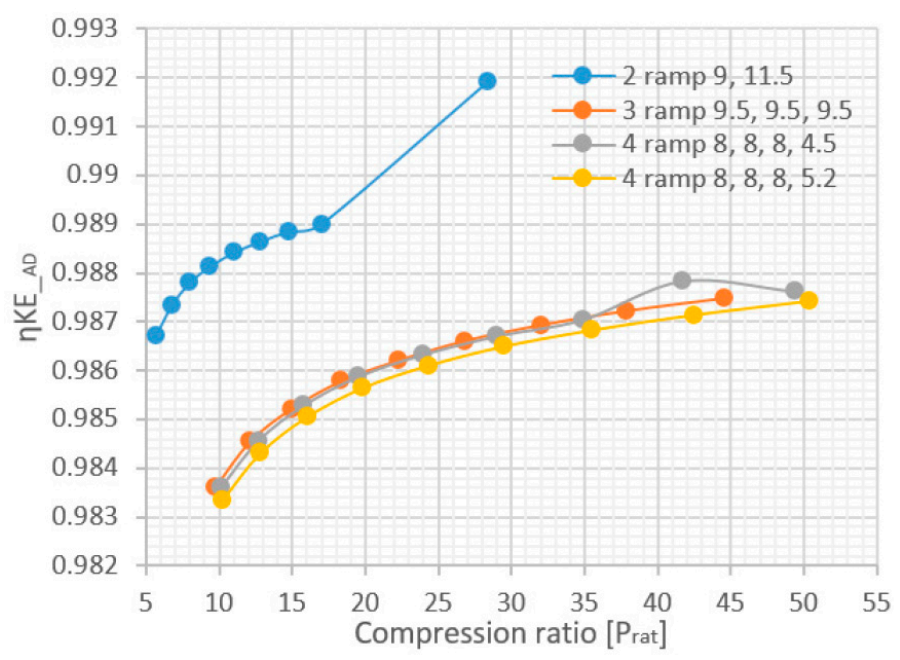

Figure 19. Adiabatic efficiency of inlets for different ramp configurations. 


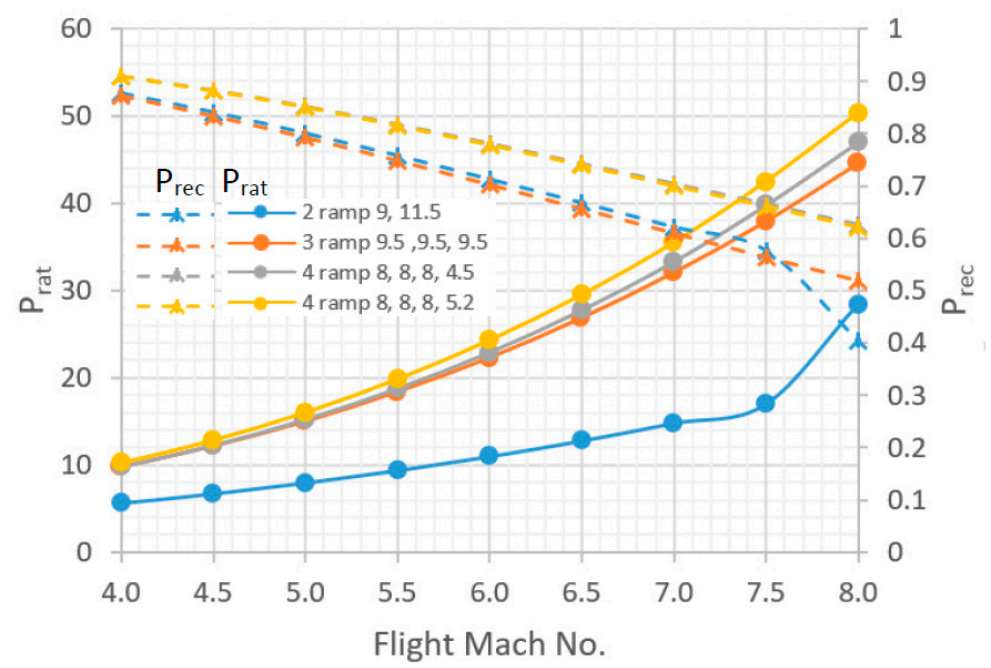

Figure 20. Theoretical compression and pressure recovery of the inlets.

\section{2-D CFD Simulations}

\subsection{2, 3 and 4-Ramp 2-D Simulation}

Initially the simulations of the refined four ramp inlet took the capture-isolator area ratio as the height equivalent into account, however this lead non-existent shock trains in the isolator for all Mach number in the operation range. Therefore, it was decided that the capture-isolator area ratio would be discarded due to time constraints of the project.

Figure 21 displays the Mach contour at flight speed of Mach 4.5, which is the speed at which the scramjet begins operating. The flow's average speed is Mach 2.7 along the centre-line of the isolator and the shock waves become detached and as a result there is flow separation at the bottom surface and slightly further downstream the flow has detached from the upper surface.

The cowl lip has been moved forward to reduce spillage when the turbojet engine is in operation.

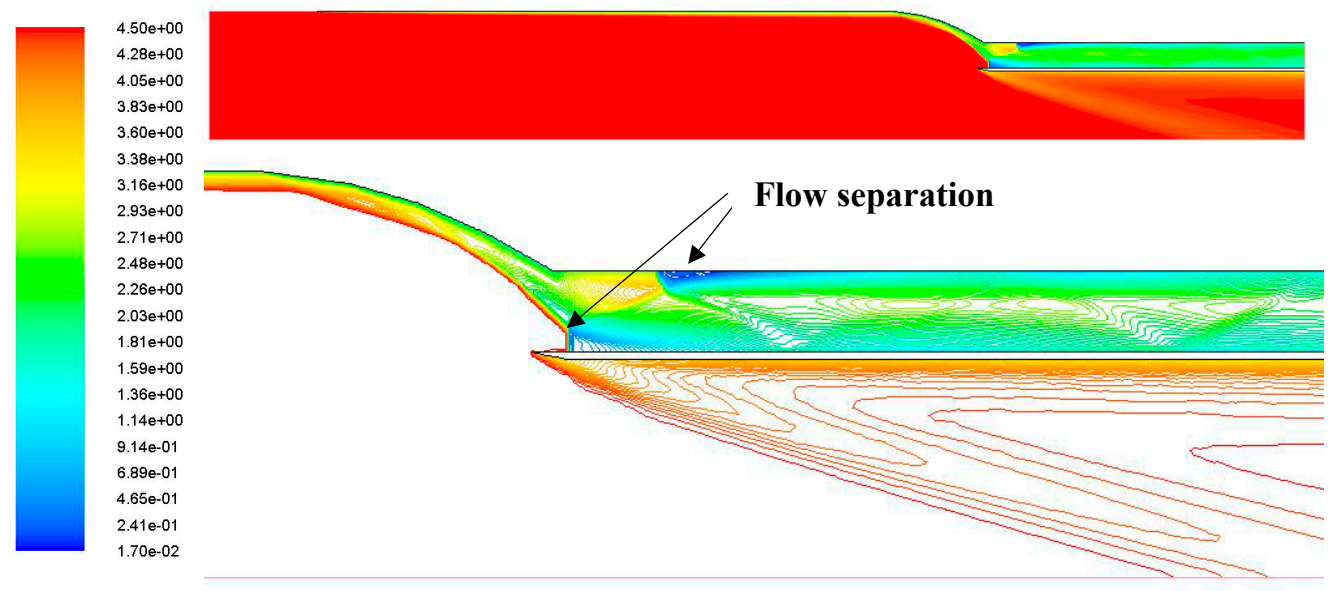

Figure 21. Mach contours of four ramp inlet at Mach 4.5.

Figure 22 displays the Mach contour at Mach 6. The shockwaves impinge at the same point at the cowl, however there is flow separation at the top surface, this is unavoidable since there is a sudden increase in flow area after the final ramp, which produces an expansion fan and the difference in velocities causes the separation. 
Figure 23 displays the Mach contour during flight at Mach 7, here we can see that the shock waves are more established and impinge at the same location on the cowl. Furthermore, a shock train propagating through the isolator can be observed, along with a relatively thin boundary layer on the upper and lower walls of the isolator. Moreover, there is no visual evidence of flow separation which was observed for Mach 4.5 and 6.

Figure 24 displays the Mach contour of the refined four ramp inlet at Mach 8, the design cruise speed. The inlet was designed to have the best performance at this speed because the cruise phase is where the aircraft will spend a majority of the flight duration. A noticeable feature is that the boundary layer on the vehicle forebody and ramp walls have become thinner with increasing flight Mach number. Additionally, oblique shock waves impinge further downstream of the cowl lip, ideally the shock waves should impinge on the cowl lip but as the scramjet needs to be designed to fly at a range of Mach numbers the cowl lip is rather forward as well as accommodate a turbojet intake. This reduces spillage drag when the vehicle is flying at lower speeds.

The unfilled contour lines allow the identification of the shock waves propagating through the isolator. An expansion fan is produced at the turn after the final ramp, identifiable by the increasing Mach number. Fust after the oblique shock waves the flow decelerates to Mach 3.48. As the flow passes through the shock train, it is decelerated and the flow speed at the isolator is stabilised at around Mach 3.24. This implies that the shock diamond formed at the isolator is relatively weak as the flow does not keep decelerating further.

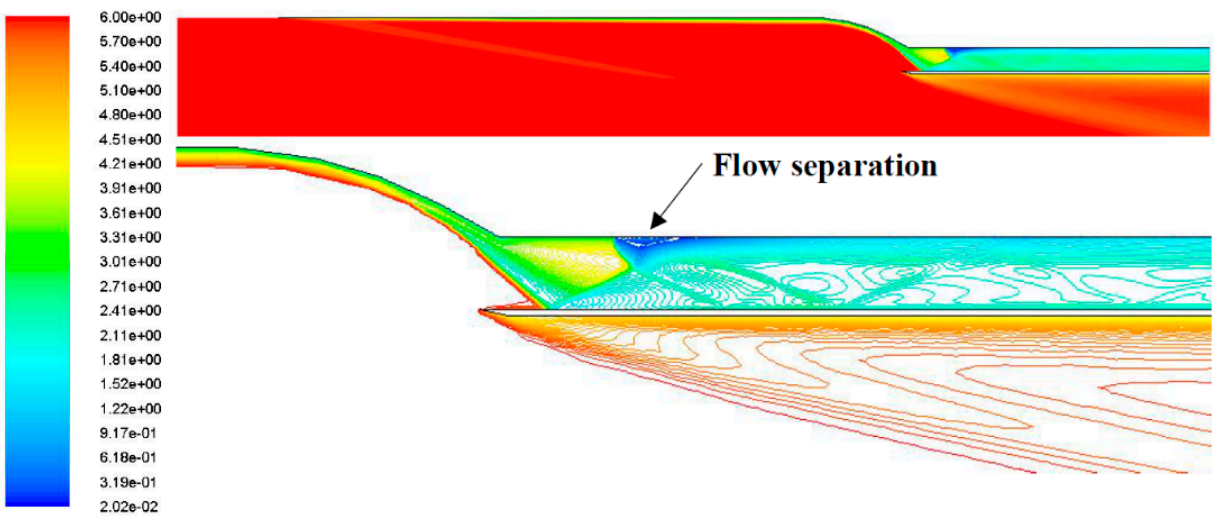

Figure 22. Mach contours of four ramp inlet at Mach 6.

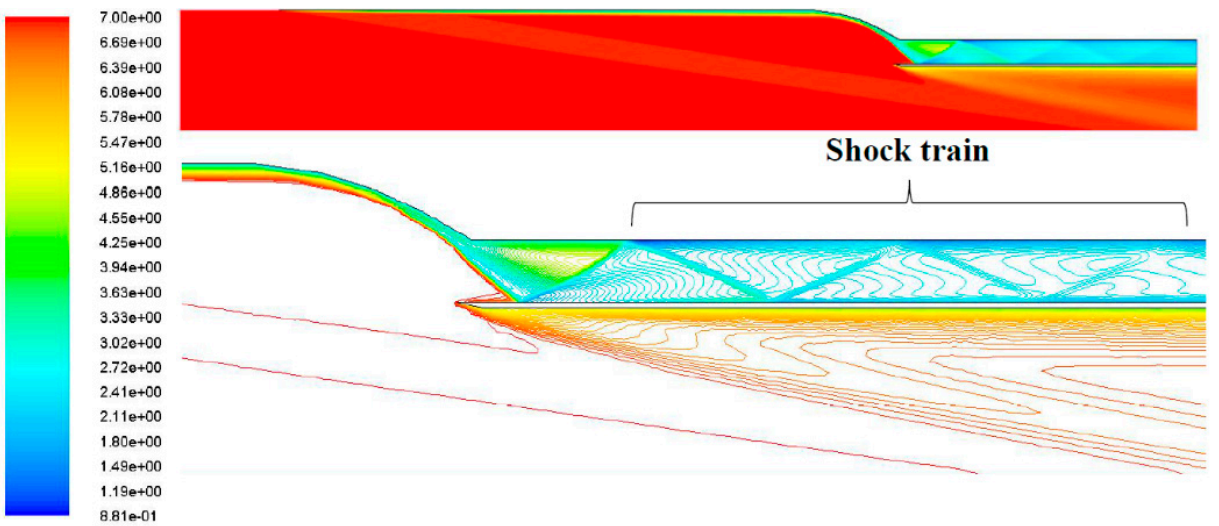

Figure 23. Mach contours of four ramp inlet at Mach 7. 


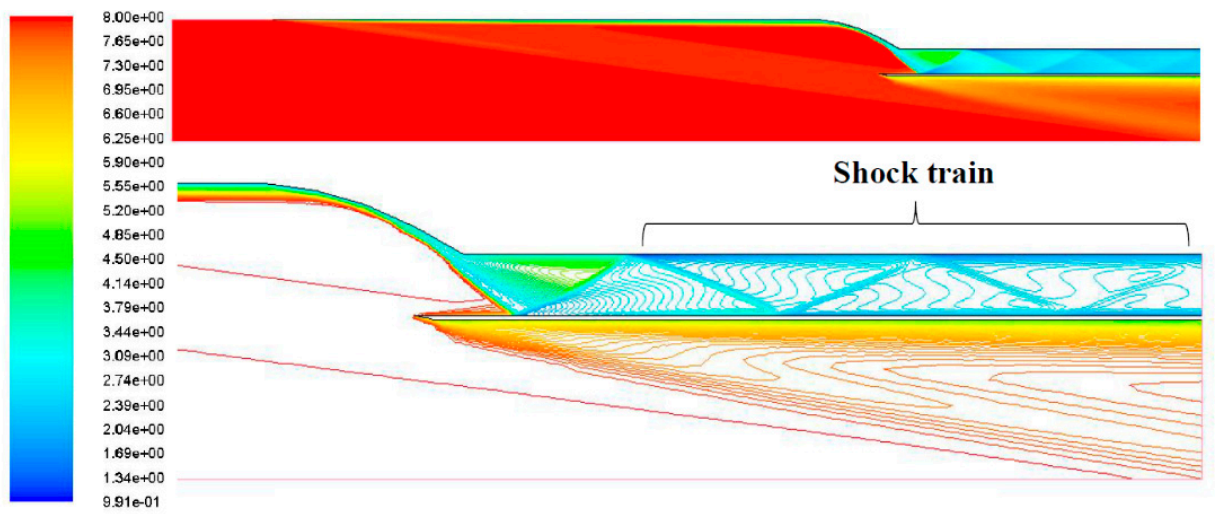

Figure 24. Mach contours of four ramp inlet at Mach 8.

Figure 25 displays the variation of the compression ratio and stagnation pressure recovery along the centreline of the isolator, from just before the shock layer produced by the combination of oblique shock waves for flight at Mach 8. The repeating peak and trough pattern is the result of the shock train, as the reflecting oblique shock wave loses momentum the properties of the flow become stable, ideal for the combustion process. The compression ratio peaked at 54 just after the final oblique shock wave but then averages to 26 in the isolator. This is higher than the 50.35 obtained using empirical equations. The stagnation pressure recovery averaged $8 \%$ in the isolator compared to the theoretical Prec of $62.2 \%$, due to the ramp lengths not being optimised fully due to project time constraints. The ramp lengths were assigned to be $1 \mathrm{~m}$ each because if it was any longer it caused the height of the inlet to be increased significantly.

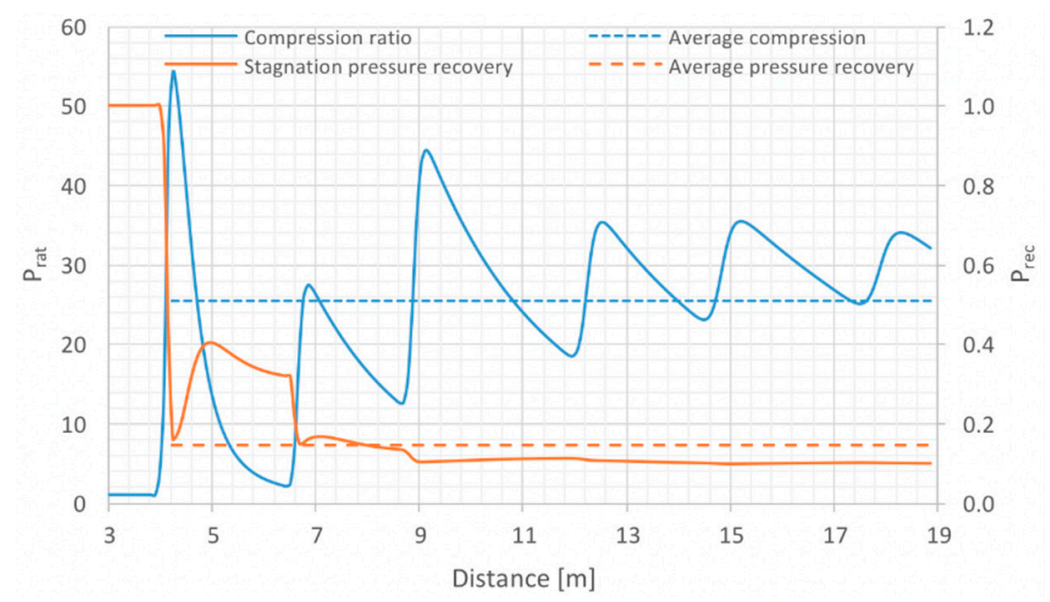

Figure 25. Performance of inlet in CFD at Mach 8.

\subsection{Comparison of Finalised 2-D Compression Systems}

The inlet does not perform well at the speed at which the scramjet begins operating Mach 4.5. The performance is not great at Mach 6 either but it has improved slightly with the reduction in flow separation but the shock train loses its structure downstream. At Mach 7 the shock train begins to establish itself, along with minimal flow separation at the wall. At the design cruise speed of Mach 8, the shock train is well established along with no visible flow separation. The results presented in the report indicate that a variable geometry inlet design would be beneficial and is being explored in the follow-on investigations of this project.

Figure 26 displays the Mach number and temperature ratio variation of the theoretical calculations and CFD results at varying Mach number. As it was identified, in the Mach contours the oblique shock 
waves combine and impinge in the same point on the cowl lip, this means that deceleration of flow occurs drastically, the data of the CFD was taken after the oblique shock wave impingement.

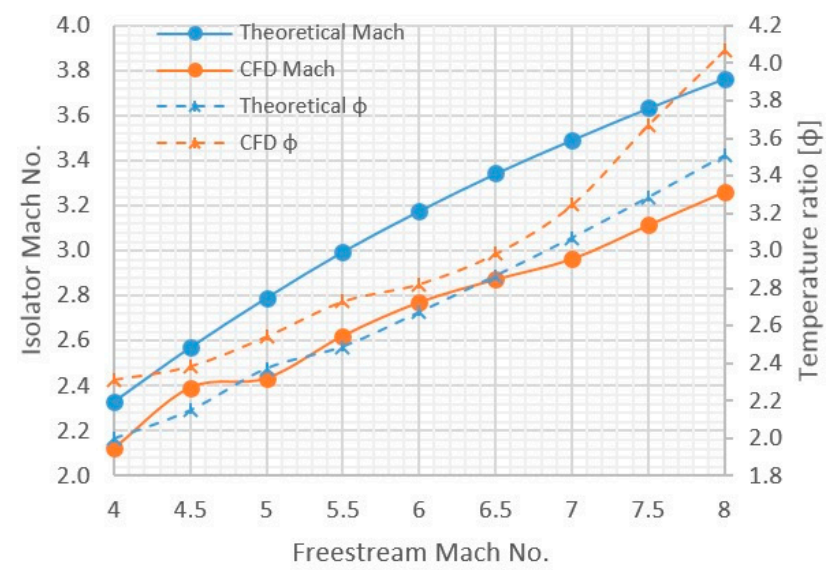

Figure 26. Graph comparing theoretical parameters with 2-D CFD results.

\section{3-D CFD Simulations and Combined Cycle Engine Configuration}

After the 2-D design is established, 3-D simulations are necessary to see the performance of the scramjet compression system in 3-D space as the previously lacking wall (in 2-D simulations) are introduced.

\subsection{3-D Computational Domain \& Computational Fluid Dynamics (CFD) Setup}

The refined four ramp 2-D inlet was converted into a 3-D model with a chamfer of $15^{\circ}$ which was applied outwards on the side walls with the purpose of mitigating the effect of a bow shock into scramjet inlet; which would destroy the flow. Furthermore, it would match the scaled scramjet inlet that is potentially going to be manufactured and tested using a hypersonic wind tunnel; this would allow accurate comparison with CFD simulation and experimental data.

The model is imported into ANSYS Fluent 17.0, Figure 27 exhibits the computational domain with half of the inlet. 3-D CFD setup involves applying a symmetry plane along the line of symmetry, this allows the meshing to be more refined with an element number of 512,000 applied in ANSYS Fluent 17.0 which proved however sufficient. Additionally, the 3-D enclosure of the computation domain has to be relatively large since the effect on the flow due to the vehicle forebody and the side walls need to be captured. The element sizing was set to $0.225 \mathrm{~m}$ for the computation domain with $0.1 \mathrm{~m}$ element sizing around the vicinity of the ramps, where the flow properties were most likely to be varied.

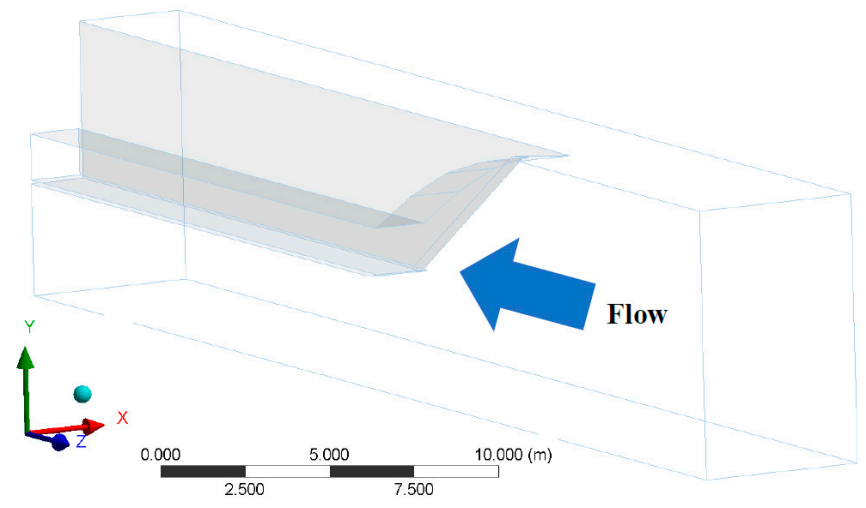

Figure 27. ANSYS Fluent 3-D computational domain setup. 
Figure 28 depicts the mesh of the scramjet. The simulations below used $1.45 \mathrm{~m}$ ( $2.9 \mathrm{~m}$ full width) as the width of the scramjet inlet and isolator, as the exact sizing was not established due to unsureness of the air mass flow requirement at the time.

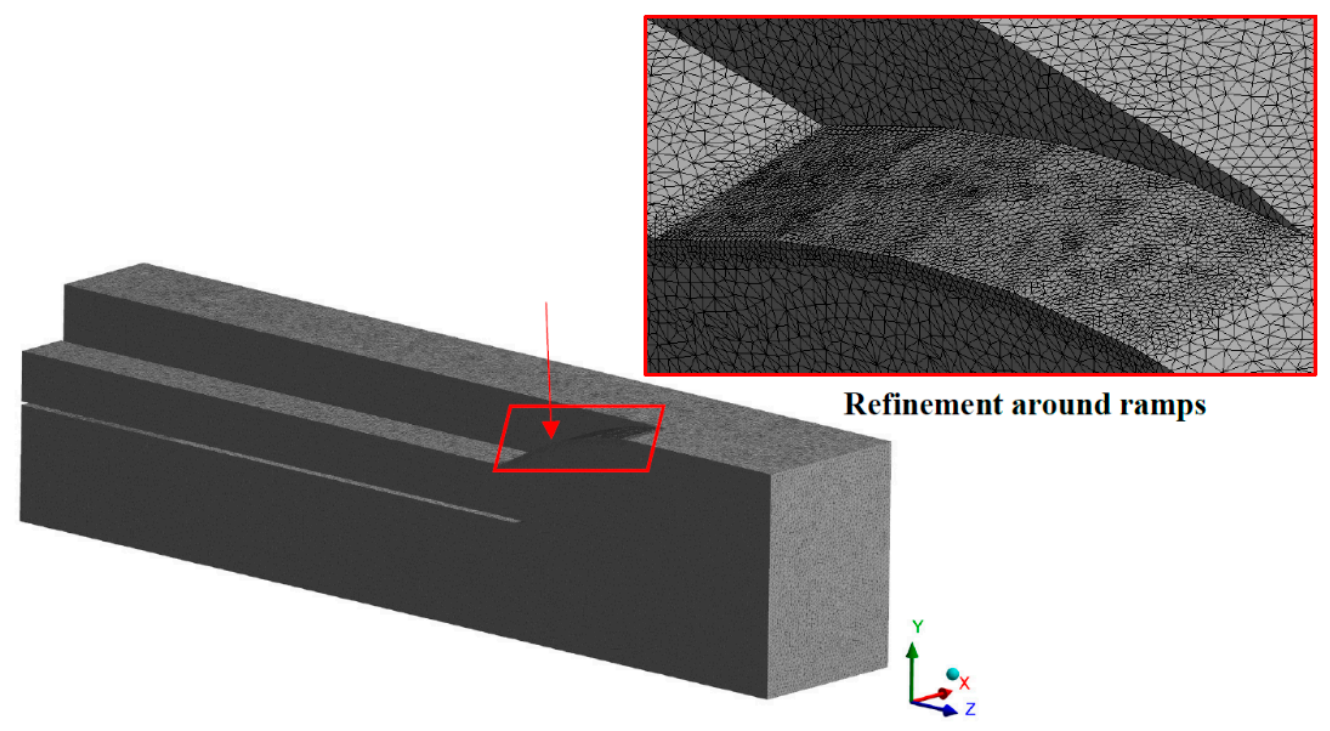

Figure 28. Computational domain 3-D mesh and refinement.

\subsection{CFD Simulation Results}

\subsubsection{Mach 4.5}

Figure 29 presents the Mach contours at the ramjet to scramjet transition speed of Mach 4.5. As it can be seen there is issues with flow separation after the impingement of the oblique shock waves just behind the cowl lip. Moreover, another flow separation occurs on the upper surface after the expansion fan. This correlates to the 2-D results, which means that the boundary condition setups used for the 2-D and 3-D simulations are coherent.

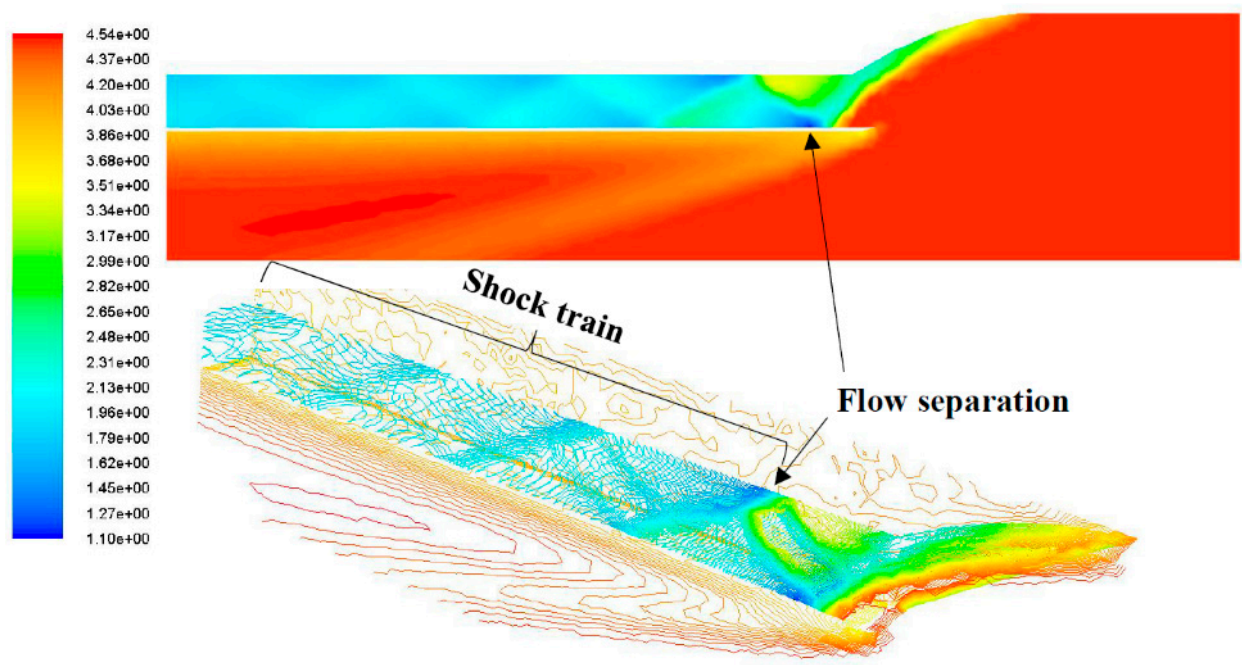

Figure 29. CFD results for 3-D inlet simulation at Mach 4.5.

The flow decelerates to speed of Mach 2 in the isolator compared to the speed of Mach 2.7 in the 2-D simulations, which is a reduction of $26 \%$. The reduction can be attributed to the addition of 
the side walls, which further increases the amount of deceleration flow due to the no-slip condition, where the fluid's velocity is reduced to zero at the wall.

The velocity vector at Mach 4.5 is displayed in Figure 30, vectors allow visualisation of the flow direction and its magnitude. Here you can see that the flow is slowed down after passing through a shock wave and being turned parallel to the wall and then being further slowed down after passing through additional shock waves. There we can also see the flow being speed up after passing through the expansion fan after the last ramp on the upper surface. The blue arrows are the region where there is flow separation due to the adverse pressure gradient and the flow not having enough energy to overcome it. This is mainly due to the geometry not being optimised for flight at Mach 4.5.

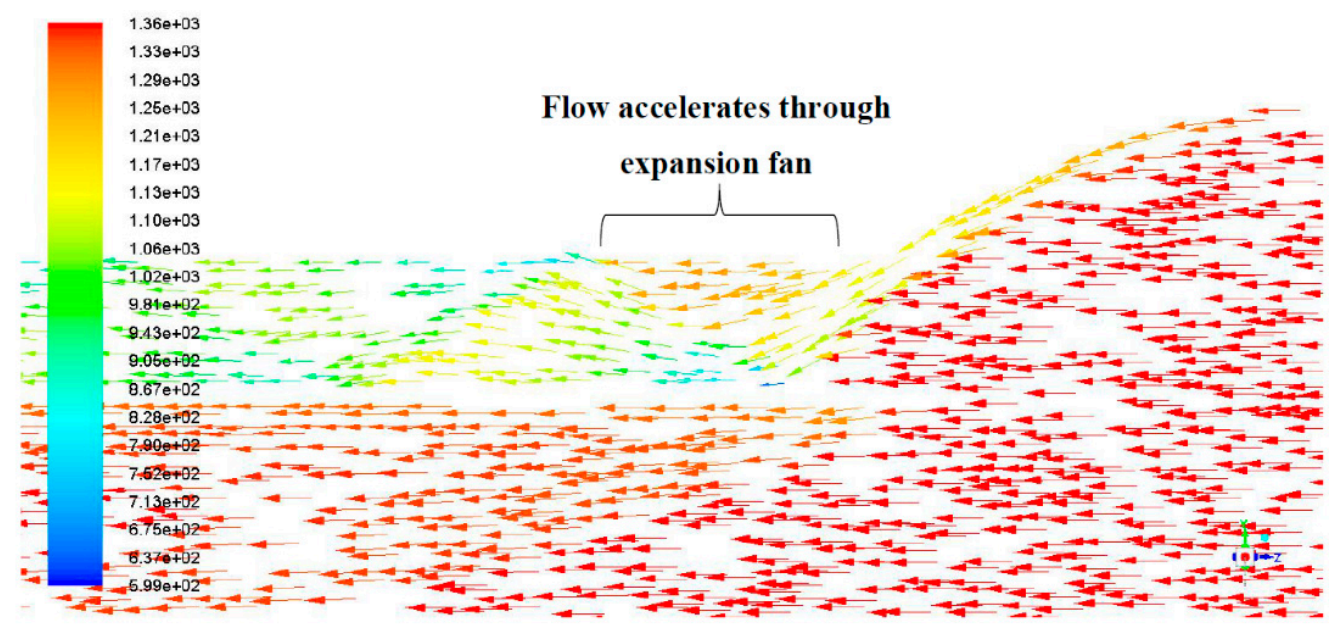

Figure 30. Velocity vectors on the symmetry plane of the 3-D inlet for flight at Mach 4.5.

Figure 31 presents the oblique shock incurred on the side wall of the scramjet inlet, a $15^{\circ}$ chamfer outwards in addition to the relatively thin wall thickness of $0.1 \mathrm{~m}$ minimises the possibility of a bow shock, which would negatively affect the operation of the inlet. If the ramjet is decided to be installed on the side of the scramjet it may cause some issues because of the shock that is generated and directed into the ramjet, which will be discussed in further later on.
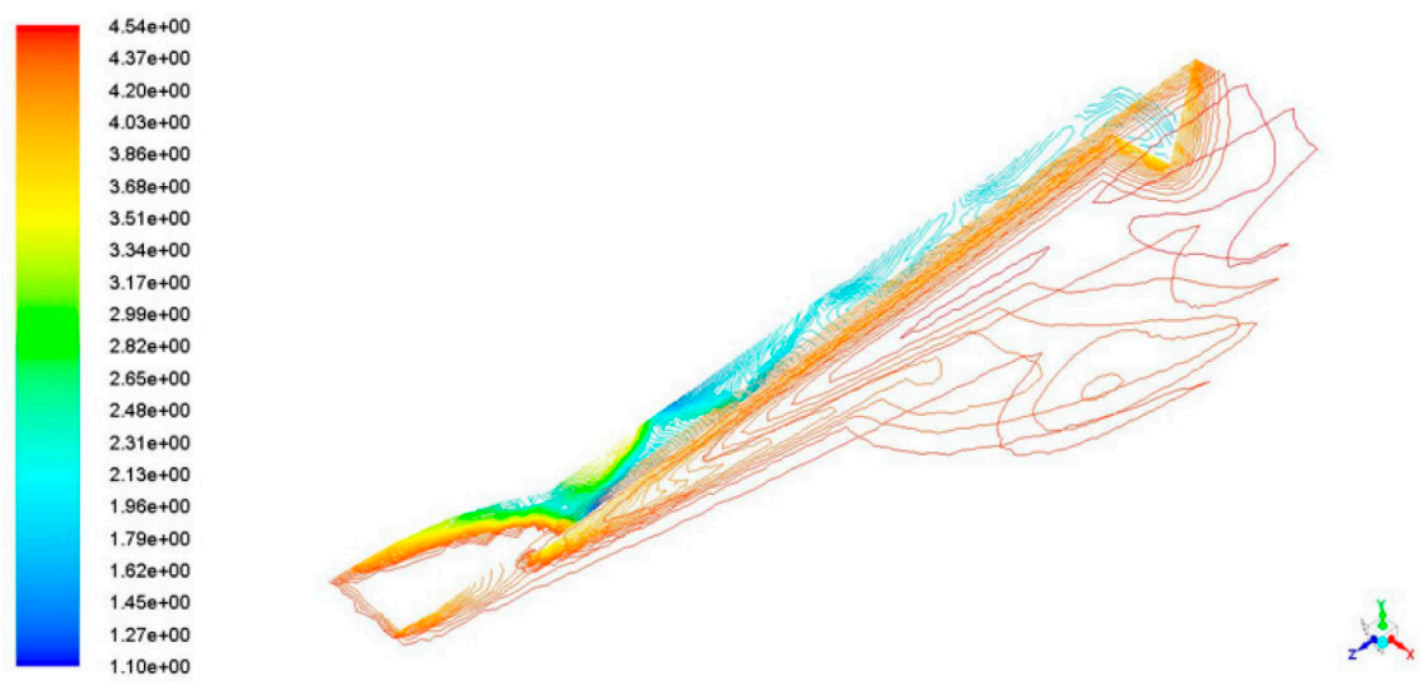

Figure 31. Oblique shock observed at the outward chamfered scramjet wall at Mach 4.5. 


\subsubsection{Mach 8}

Figure 32 displays the Mach contours during flight at Mach 8. On the side view the impingement of the shockwave is downstream of the cowl lip. A shock train can be seen to formulate, however it does not fully extend along the whole length of the isolator, whereas for the 2-D simulation the shock train profile propagates until much further downstream of the isolator. The reason for this is because the flow is being exposed to further deceleration caused by the presence of the wall in the 3-D geometry.

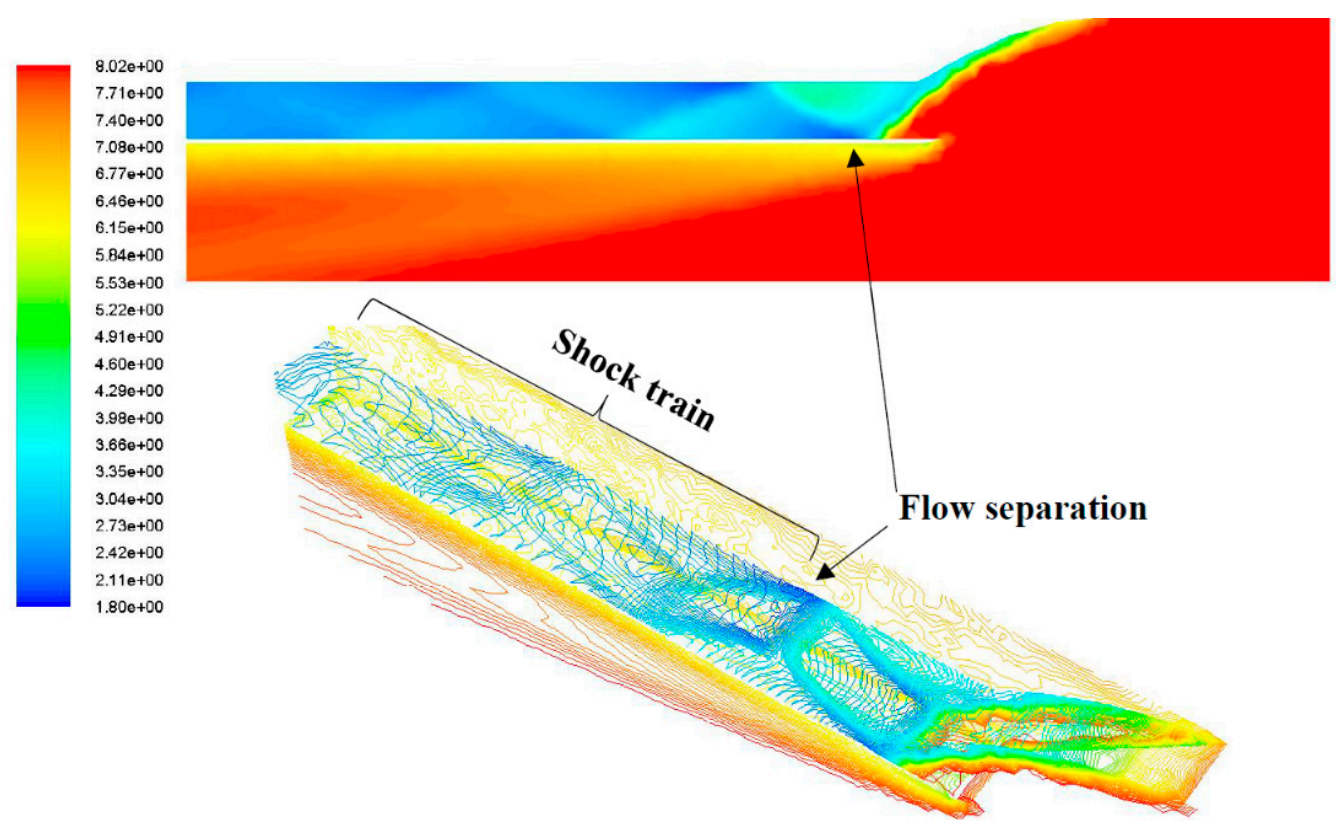

Figure 32. Computational Fluid Dynamics (CFD) results for 3-D inlet simulation at Mach 8.

On the 3-D isometric view of the unfilled Mach contour the effect of the side walls is clearly observable by the concentration of the contour lines around the vicinity of the side wall. Here the development of the deficient shock train is more evident. Furthermore, the effect of the shock layer from the vehicle's forebody is much more pronounced than on the 2-D simulation. These results displayed show that operation of a scramjet inlet is much different and complicated in 3-D when compared to the 2-D simulations.

The velocity vectors at Mach 8 is seen in Figure 33. Due to the almost doubling of flight speed (from Mach 4.5 to 8 ) it can be seen that the deflection angle of the flow after passing through an oblique shock wave is lower resulting in a thinner shock layer at the wall and the flow higher velocity after the shocks. Consequently, the flow has greater kinetic energy to overcome the adverse pressure gradient and minimise flow separation. Resulting in the shock train to propagate much further downstream than during flight at Mach 4.5.

At the cruise flight speed of Mach 8, the oblique shock wave formed at the scramjet walls ismuch much closer to the wall (as seen in Figure 34); here there may be possibilities of shock-boundary layer interactions. Consequently, this would still lead to flow separation in the ramjet inlet if it was decided that the ramjet would be positioned adjacent to the scramjet. 


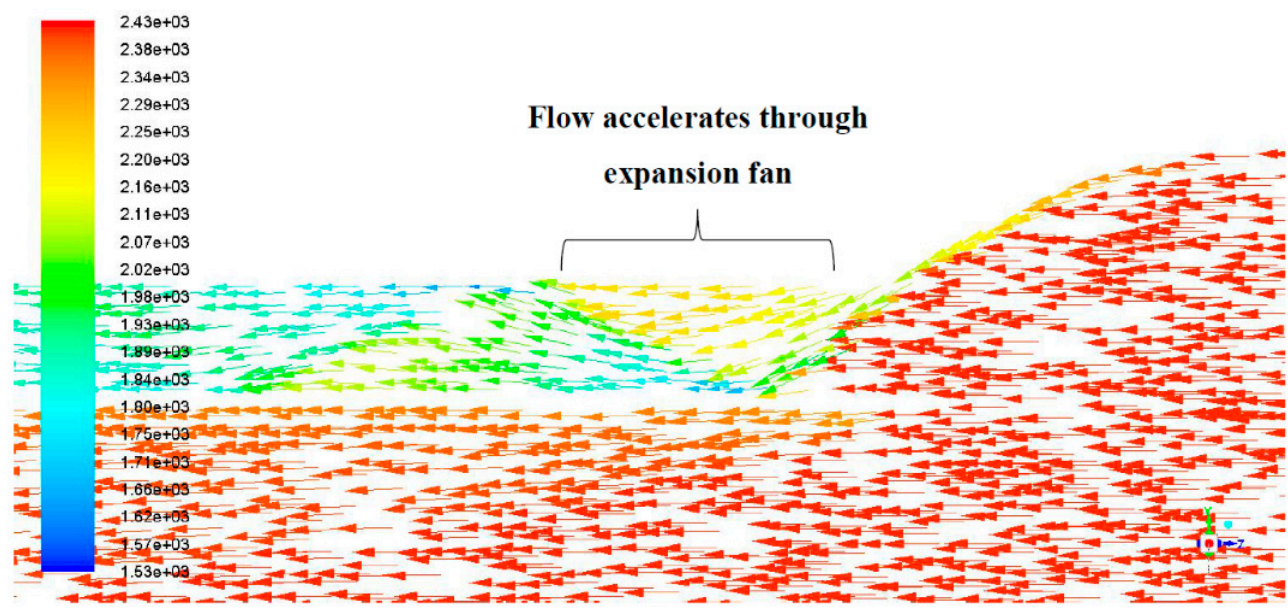

Figure 33. Velocity vectors on the symmetry plane of the 3-D inlet for flight at Mach 8.
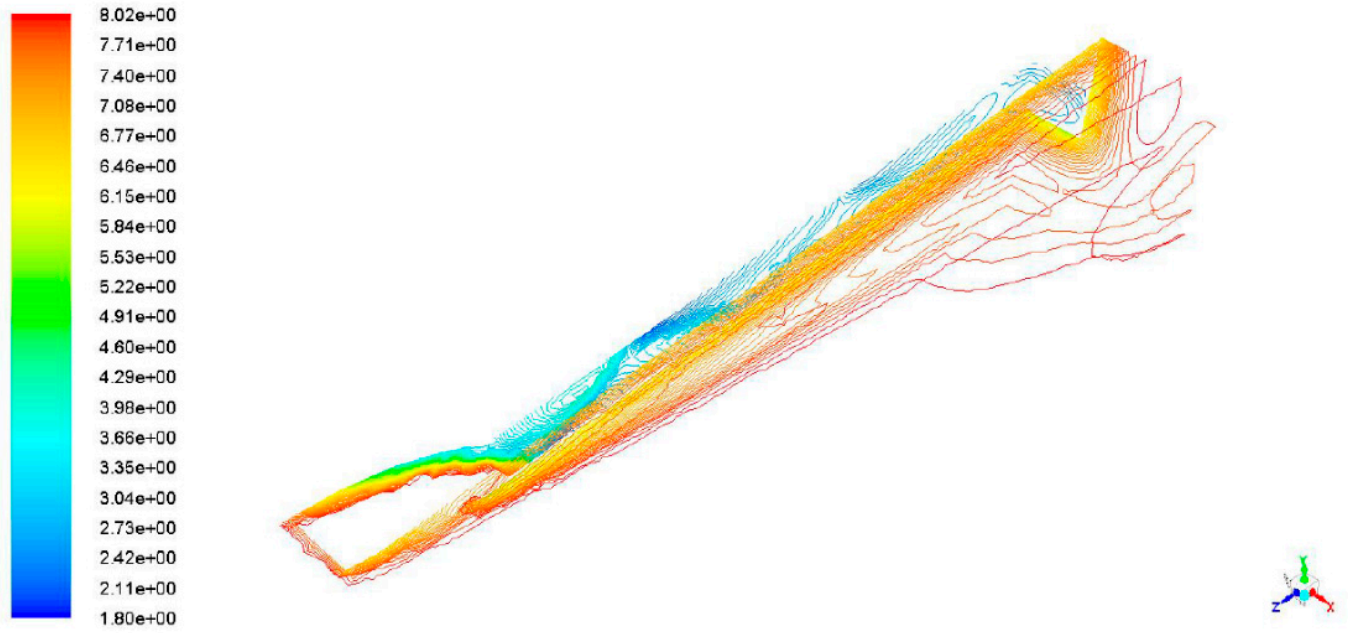

Figure 34. Oblique shock observed at the outward chamfered scramjet wall at Mach 8 .

\subsubsection{Comparison of Performance at Different Mach Speeds}

From the 3-D simulations of the scramjet compression system, it can be seen that the inlet has been optimised to operate at the cruise speed of Mach 8, where the vehicle will spend a majority of the flight duration. However at Mach 4.5 (the transition speed), the CFD simulations indicate that the scramjet inlet will not perform well because of the lacking shock train necessary to provide 'good quality' air to the combustor.

\subsubsection{Combined Cycle Engine Configuration}

The compression system designed in this project was part of the overall hypersonic propulsion system. Before the inlet and isolator of the scramjet were even designed, potential layouts of the engines and integration with the vehicle were investigated, because almost all hypersonic air-breathing ramjet and scramjet engines use the forebody of the vehicle as the external compression surfaces and the vehicle's aft body as the expansion surface. Furthermore, the position of the engines and the sizing limits that the vehicle would be able to accommodate had to be decided [16,17]. It was established that the scramjet would be set in the middle and a pair of ramjets would be attached on either side. Each of the scramjet and ramjets was designed with an integrated turbojet engine needed to take the transport vehicle from rest to Mach 2.5, the speed at which the ramjet begins operation. 


\subsubsection{Integration with Turbojet Intake}

It was decided that turbojet engines were to be integrated in an over-under layout with the scramjet and ramjet engines so that it was within the vehicle, thus minimising drag, which would be expected if the turbojet engines were attached externally on the vehicle. The other option was to use a wrap-around configuration; but it would mean that a large structure with a diameter of between 2-2.5 $\mathrm{m}$ and struts to hold it into place would have to be implemented at the middle of the scramjet or ramjet. This would detrimentally affect the flow structure and would be especially difficult to integrate with the scramjet which has hypersonic flow throughout the whole system.

In the over-under configuration the turbojet is located above the scramjet after the ramps (as seen in Figure 35), the intake is hidden by the retractable flaps that are initially open during take-off and low supersonic flight. At Mach 2.5 the ramjet is operational and the flaps are retracted to shut off air supply to the turbojet intake; here, the scramjet whole scramjet intake is shut off using retractable flaps to reduce the drag as the scramjet only starts operating at Mach 4.5, where they open again. The scramjet and ramjet work together until the vehicle reaches Mach 5 , at this speed the ramjet intakes are shut off with a pair of retractable flaps, else the normal shock waves produced in the non-operating ramjet would substantially increase drag.

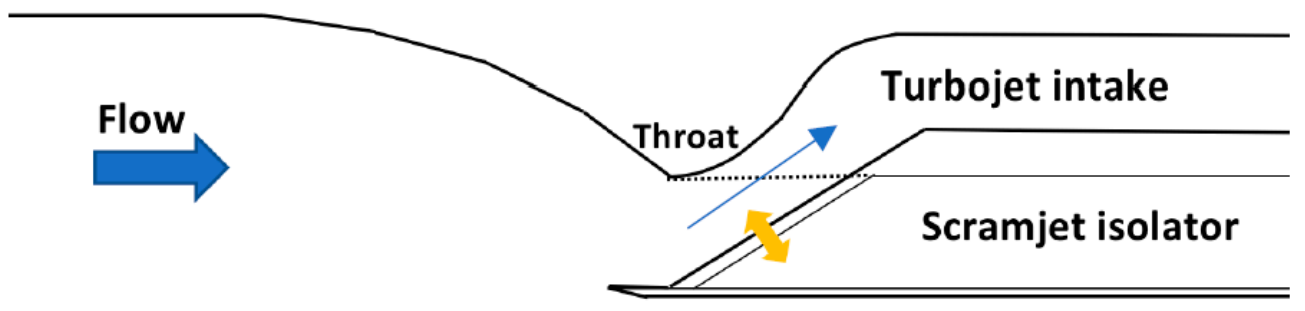

Figure 35. Diagram of the over-under configuration of the scramjet and turbojet engine.

The Mach contour of the turbojet intake operating at Mach 2.4 can be seen in Figure 36, just before the ramjet begins operation at Mach 2.5. The flap allows airflow to get routed into the turbojet intake, the intake has been shaped with a throat in order to induce a normal shock, hence subsonic air can be provided to the turbojet engine. For Mach 2.4 flight and this particular geometry it can be seen that the flow velocity has been reduced to $\sim$ Mach 0.24 downstream of the normal shock.

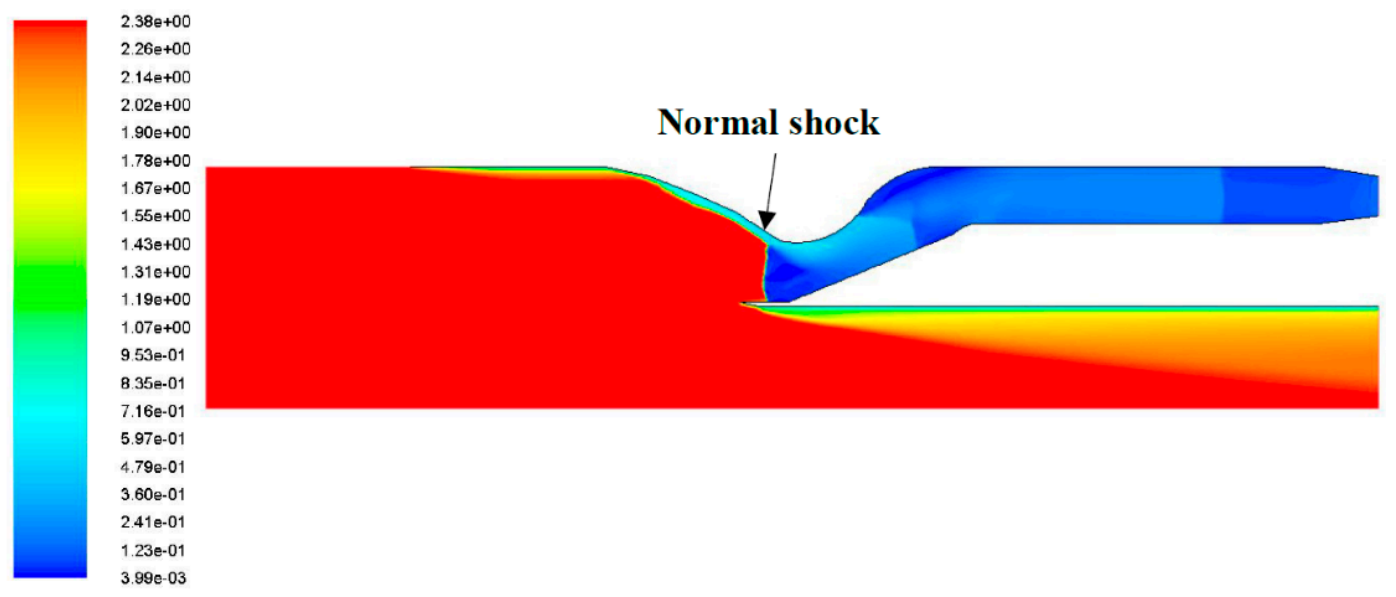

Figure 36. Mach contour of the over-under turbojet-scramjet hybrid engine in turbojet mode.

In the example above, the inlet is operating at the critical mode, where the normal shock is placed at the cowl lip. Ideally the inlet needs to operate in the supercritical mode, where the normal shock 
should be positioned after the throat in order to minimise the chance of an engine unstart. However, it takes a very long iterative process of changing the geometry at both the throat region and chocking region after where the turbojet is placed in order to induce the normal shock at the ideal position. Furthermore, at this stage the sizing of the turbojet engine was not available thus the geometry of the turbojet intake was approximated (to $2 \mathrm{~m}$ ) for it to be fitted within proximity of the scramjet engine, so that minimal space from the vehicle was occupied. As with the inlet, the exhaust plume produced by the turbojet will exit the vehicle through retractable flaps that open somewhere in the expansion surface of the scramjet.

\subsubsection{Scramjet-Ramjet Integration}

There are many ways the engines could be arranged on the vehicle; since the ramjet and scramjet have two different purposes, the arrangement had to be symmetric so that the vehicle would fly forwards in the longitudinal direction. Two arrangements were considered, the first was placing the scramjet in the middle with a pair of ramjets on either side in the same orientation as seen in Figure 37a, the second had the ramjets attached $90^{\circ}$ so that the ramjet ramps formed the walls of the scramjet as seen in Figure 37b. This would also allow the vehicle's forebody to be solely used as the external compression surface for the scramjet. In addition, the ramjet nozzle is usually converging-diverging and conical in shape so it wouldn't need to be expanded using the aft of the vehicle.

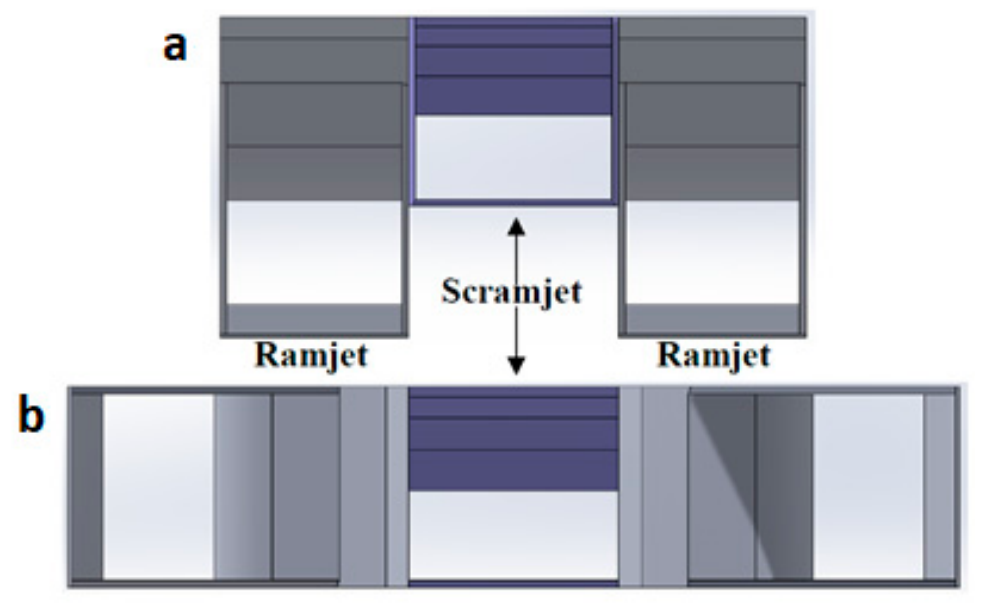

Figure 37. (a) Engines in the same orientation; (b) Ramjets rotated $90^{\circ}$.

With the engines in the same orientation, it can clearly be noticed that the ramjet inlet $(4.6 \mathrm{~m})$ is significantly taller than the scramjet inlet $(2.771 \mathrm{~m})$. Whereas, if the ramjet is rotated $90^{\circ}$ the width of the inlet can be easily changed to match the height of the much shorter scramjet.

\subsubsection{Same Orientation Scramjet and Ramjet Layout}

Figure 38 displays the Mach number contours of the symmetry plane for the combined same orientation ramjet and scramjet inlets in 3-D. The shock structure observed here is comparable simulations conducted for the scramjet inlet by itself. The oblique shock at the cowl lip is more prominent due to the influence of the adjacent taller ramjet. 


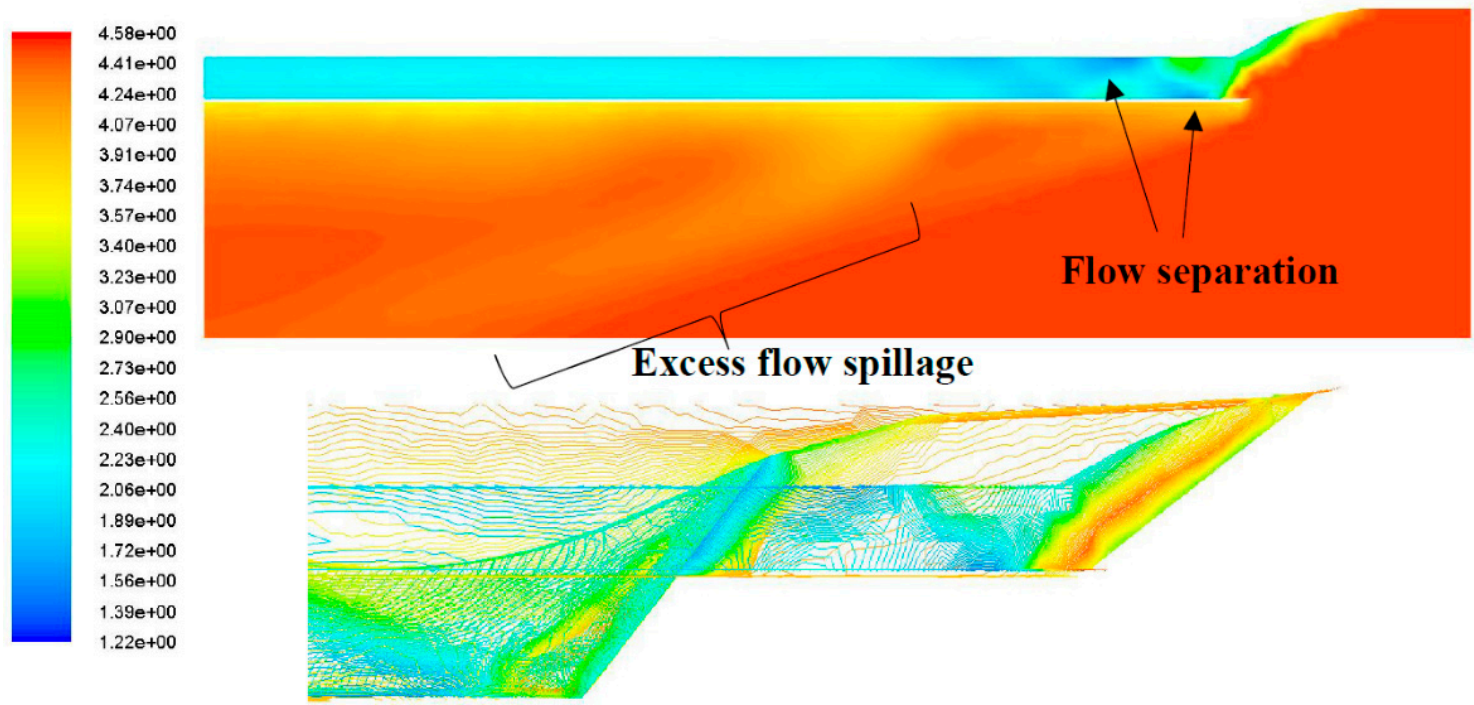

Figure 38. Mach contour of same orientation ramjet and scramjet inlets at Mach 4.5.

Figure 39 shows an isometric view of the unfilled Mach contours at the transition flight speed of Mach 4.5; here, the presence of the oblique shock waves stemming from the sharp edges of the ramps and walls of the scramjet can clearly be seen. The flow inside the ramjet also becomes supersonic throughout the inlet and the normal shock has been pushed back to the exit of the inlet, where the fuel injectors are placed, this would detrimentally affect the performance of the ramjet inlet.
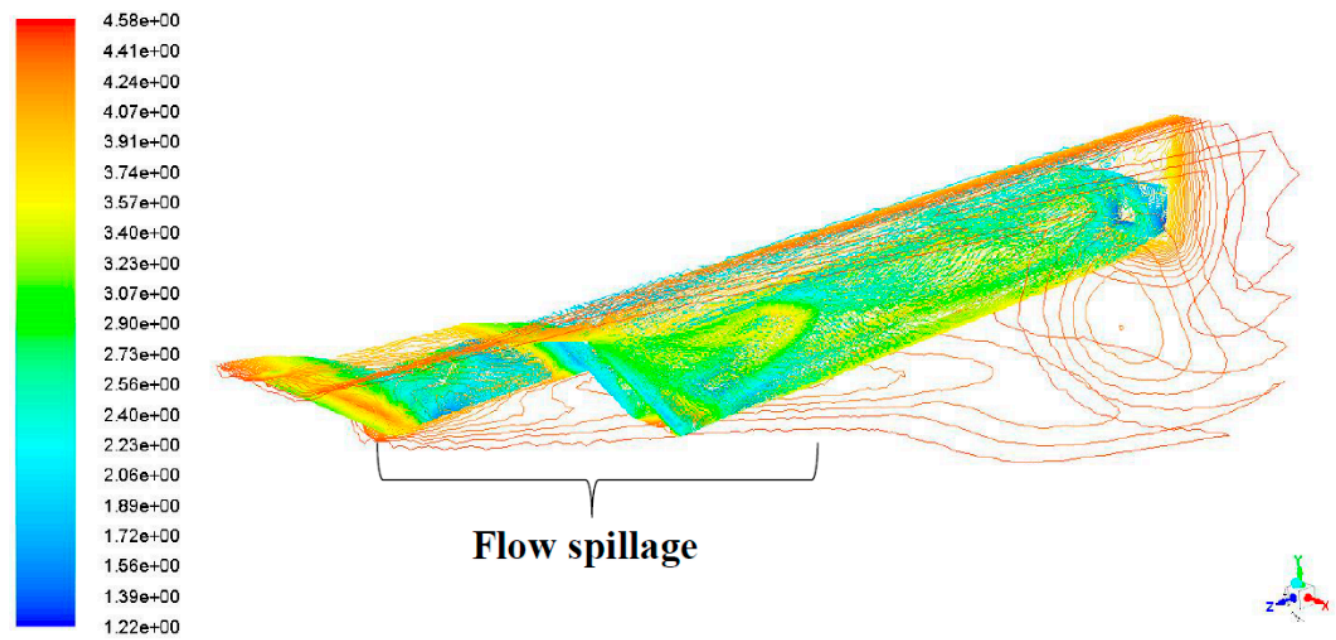

Figure 39. Oblique shock generated at scramjet wall at Mach 4.5.

Figure 40 displays the Mach contour of the scramjet inlet as seen from the symmetry plane. The flow structure in terms of deflection and shock train inside the isolator is similar to the individual scramjet inlet CFD simulations. It can be seen that at Mach 8 the ramjet is supersonic throughout the whole inlet.

Figure 41 displays the isometric view of the unfilled Mach contour of the ramjet and scramjet inlets at Mach 8. The oblique shock wave emanating from the sharp edge wall of the scramjet are directed into the ramjet, this is unfavourable as it will interfere with the shock structure needed by the ramjet to operate efficiently, however after Mach 5 the ramjet intake will be closed off with retractable flaps and solely the scramjet will accelerate the vehicle to Mach 8. 


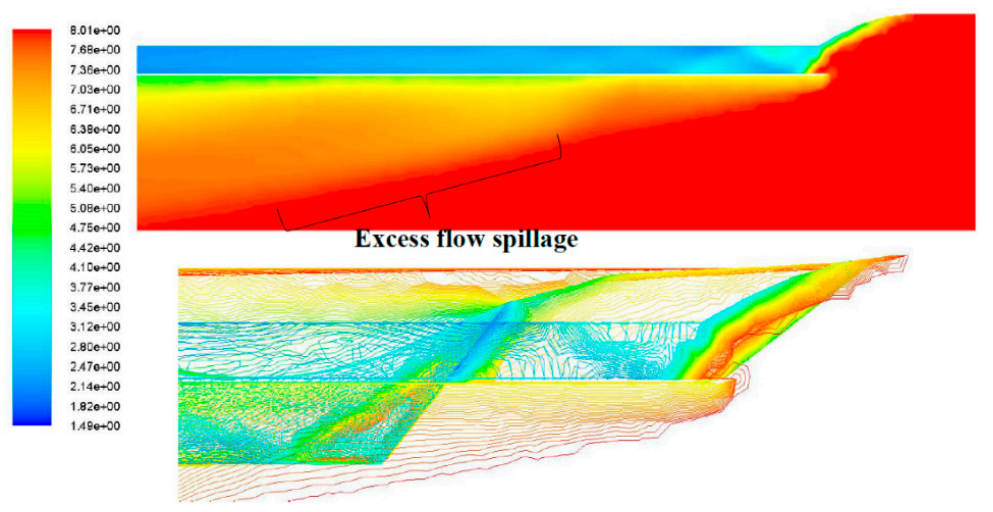

Figure 40. Mach contour of same orientation ramjet and scramjet inlets at Mach 8 .

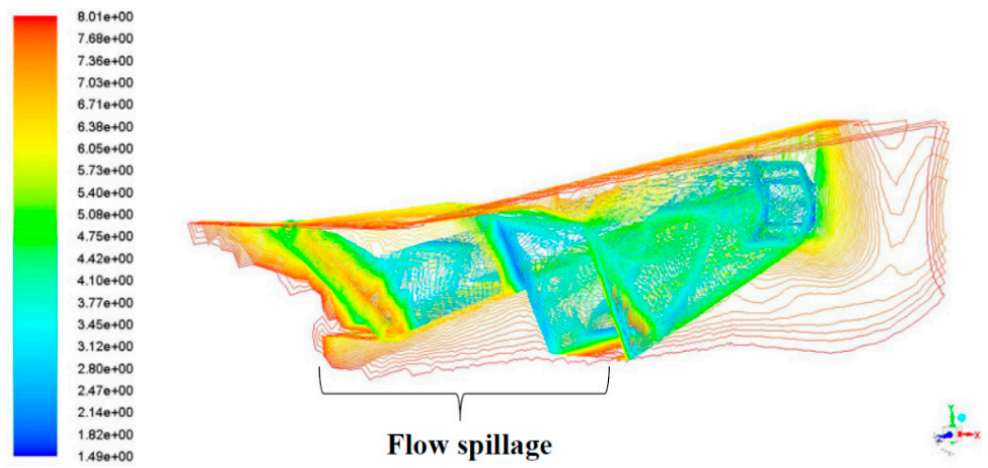

Figure 41. Mach contour of same orientation ramjet and scramjet inlets at Mach 8 .

\subsubsection{Rotated Ramjet Layout}

The other method (shown in Figure 37b) has the ramjets rotated at $90^{\circ}$, so that the ramps of the ramjet make up the walls of the scramjet. This layout mitigates the issue with the oblique shock wave protruding from the scramjet walls into the ramjet inlet observed in Section 7.2.7 This arrangement also allows for the total height of the engine to be reduced because the height of the scramjet is $2.771 \mathrm{~m}$ (distance from bottom surface of cowl lip to forebody), whereas the ramjet is $4.6 \mathrm{~m}$ tall.

Figure 42 displays the Mach contours at Mach 4.5, here the shock wave impingement downstream of the ramp is very similar to the simulations for the inlet by itself. There is still a problem of flow separation as it can be seen, however the shock train manages to propagate three cycles and then diffuses but still stays supersonic.

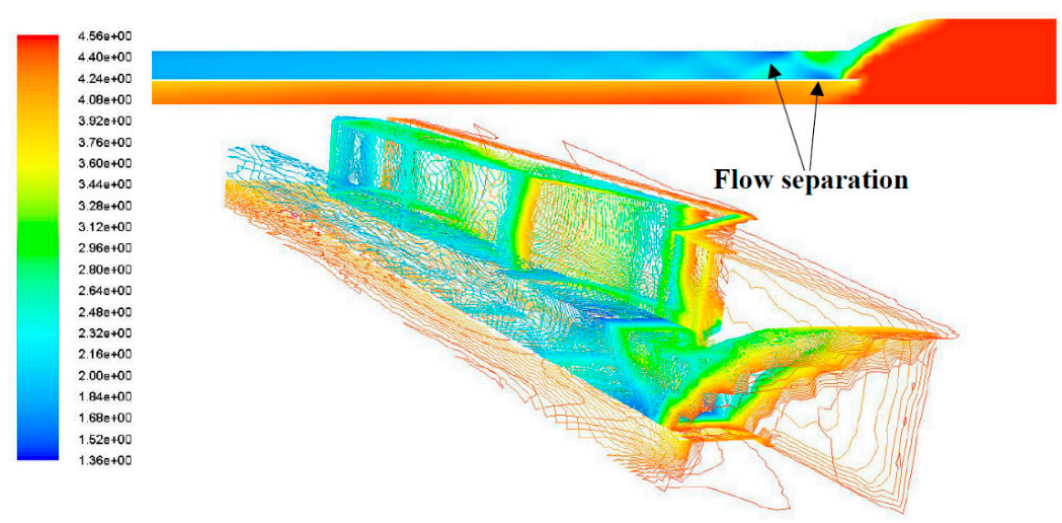

Figure 42. Mach contour of the rotated ramjet inlets at Mach 4.5. 
Figure 43 presents the Mach contour at the cruise speed of Mach 8. Similarly to the flight at Mach 4.5 the shock train only extends 3 periods, however since the streamwise velocity is much greater the total length is much longer. The velocity stabilises at around Mach 2.47 in the isolator.

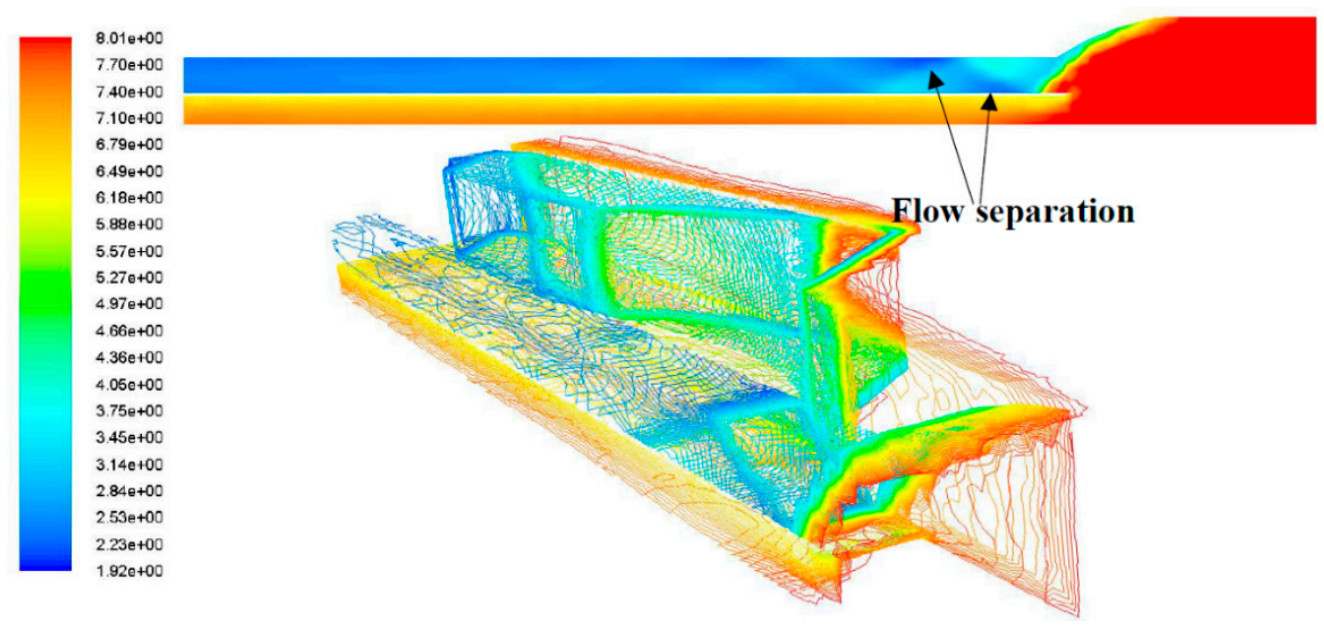

Figure 43. Mach contour of the rotated ramjet inlets at Mach 8.

\section{Conclusions}

An investigation was conducted to develop a scramjet compression system to be used as part of a combined cycle propulsion system that propels a transport aircraft and achieves sustained Mach 8 flight at an altitude of $100,000 \mathrm{ft}$.

The procedure began with using empirical formulas and shock relation charts to explore performances of inlets with varying number of ramps and deflection angles. The shock structure of these design was analysed using ANSYS Fluent 17.0 to conduct RANS CFD. A four ramp inlet with deflection angles of $\theta 1=8^{\circ}, \theta 2=8^{\circ}, \theta 3=8^{\circ}$ and $\theta 4=5.2^{\circ}$ was deemed to be the optimal solution because theoretically it achieved a compression ratio and stagnation pressure recovery of 50.3 and $62.2 \%$, respectively. The deceleration and compression of the flow after passing through oblique shock waves were comparable to the theoretical formulas.

Two possible methods of integrating the turbojet with the scramjet were explored, where it was found that an over-under configuration was the better option; as it allowed separation of the turbojet and scramjet intakes. It also avoided having a large structure capsuling the turbojet engine in the flow path and disrupting the shock structure. A basic 2-D geometry confirmed that it was possible to induce a normal shock at the inlet by having a throat in the turbojet intake, thus reducing the airflow to subsonic speeds. The normal shock was located just downstream of the cowl lip meaning that the engine was prone to being subjected to engine unstart. Further geometry refinement is needed to place the shock downstream of the inlet throat in the supercritical mode, thus mitigating engine unstart.

Two different methods of arranging the scramjet and ramjet inlets were explored. The first method was to have the scramjet inlet in the centre with two ramjets on either side in the same orientation. This method adversely permitted oblique shock waves stemming from the scramjet wall to be directed into the ramjet inlet, disrupting the operation of the ramjet. The second method consisted of rotating the ramjets on either side and using the ramjets' ramp as the walls of the scramjet, solving the issue observed in the first method. Additionally, this allowed the much taller ramjet $(4.6 \mathrm{~m}$ in straight orientation) to be shortened and matched with the scramjet compression system height $(2.771 \mathrm{~m})$. The rotated method allowed the shock structure in both the scramjet and ramjet to be more pronounced and stable. This method was to be used in the final configuration of the engine integration with the vehicle. 
2-D CFD analysis of the full scramjet showed that the oblique shock impingement and shock train structure in the isolator was found to be in identical positons at flight speed of Mach 8 for cold flow (with fuel injection) and full combustion simulations. Therefore, it can be concluded that the scramjet compression system was working well because the objective of the isolator is to 'isolate' the oncoming flow and stop perturbations of the combustor propagate upstream. Furthermore, the simulations proved that the compression ratio upholds where or not the combustion takes place (assuming that the vehicle without combustion is flying at Mach 8 regardless).

The scramjet compression system was designed to work best at Mach 8 , therefore at other flight speeds the shock structure was less efficient. The Mach cone produced by the nose of the vehicle decelerated the flow to Mach 7 before the flow reached the scramjet inlet. This reduction in flow speed meant that the levels of compression achieved was not as great as for the simulations of the inlet by itself and the full scramjet. Regardless, data taken from the scramjet combustion simulations found that the scramjet produced $6855 \mathrm{kN}$ of thrust, whereas the final optimised aircraft had a drag of only $2710 \mathrm{kN}$, hence is it possible to achieve sustained flight at Mach 8. Furthermore, even though the stagnation pressure recovery in the simulations was found to be poor, the achievable range of the finalised aircraft was found to cover the distance between New York (JFK Airport) and London (Heathrow Airport) in about half of the time taken by the Concorde.

Author Contributions: A.P. conceived and designed the experiments and put forward the research concept ideas behind the project; D.S. and A.L. performed the experiments, analysed the data and wrote the first draft.

Funding: This research received no external funding.

Conflicts of Interest: The authors declare no conflict of interest.

\section{References}

1. Siddiqui, A.M.; Ahmed, G.M.S. Design and Analysis on Scramjet Engine Inlet. Int. J. Sci. Res. Publ. 2013, 3.

2. Heiser, W.; Daley, D.; Pratt, D. Hypersonic Airbreathing Propulsion; American Institute of Aeronautics and Astronautics: Washington, DC, USA, 1994; ISBN 978-1-56347-035-6.

3. Goyne, C.; Cresci, D. Hy-V program overview and status. In Proceedings of the 15th AIAA International Space Planes and Hypersonic Systems and Technologies Conference, Dayton, OH, USA, 28 April-1 May 2008.

4. Smayda, M.G.; Vogel, P.D.; Schultz, I.A.; Hanson, R.K.; Foelsche, R.; Tsai, C.Y.; Cresci, D.; Goyne, C.P. Hypervelocity testing of a dual-mode scramjet. In Proceedings of the 50th AIAA Aerospace Sciences Meeting Including the New Horizons Forum and Aerospace Exposition, Nashville, TN, USA, 9-12 January 2012.

5. Slater, J.; Saunders, J. Increased mach number capability for the NASA Glenn 10x10 supersonic wind tunnel. In Proceedings of the 34th JANNAF Airbreathing Propulsion Conference, Albuquerque, NM, USA, 8-11 December 2014.

6. Smart, M.K. How Much Compression Should a Scramjet Inlet Do? AIAA J. 2012, 50, 610-619. [CrossRef]

7. Waltrup, P.J.; Billig, F.S.; Stockbridge, R.D. Engine sizing and Integration Requirements for Hypersonic Airbreathing Missile Applications. Available online: www.dtic.mil/dtic/tr/fulltext/u2/a115370.pdf (accessed on 20 February 2017).

8. Smart, M.K. Scramjet Inlets; RTO-EN-AVT-185; NATO Science and Technology Organizatoin: Neuilly sur Seine, France, 2010; pp. 1-24.

9. Kotteda, V.M.K.; Mittal, S. Instabilities in Air Intakes of Supersonic Air Vehicles. Directions. Available online: https:/ / www.iitk.ac.in/aero/research-areas (accessed 22 February 2017).

10. Matsuo, K.; Mochizuki, H.; Miyazato, Y.; Gohya, M. Oscillatory characteristics of a pseudo- shock wave in a rectangular straight duct. JMSE 1993, 36, 222-229. [CrossRef]

11. Surzhikov, S.; Seleznev, R.; Tretjakov, P.; Zabaykin, V. Unsteady thermo-gasdynamic processes in scramjet combustion chamber with periodical input of cold air. In Proceedings of the 50th AIAA/ASME/SAE/ASEE Joint Propulsion Conference, Cleveland, OH, USA, 28-30 July 2014.

12. Hall, N. Ramjet/Scramjet Thrust. NASA Glenn Research Center, 2017. Available online: https://www.grc. nasa.gov/www/k-12/airplane/ramth.html (accessed on 18 March 2017). 
13. Segal, C. The Scramjet Engine: Processes and Characteristics; Cambridge University Press: Cambridge, UK, 2009.

14. Storm, R.; Skor, M.; Koch, L.D.; Bensor, T.; Galica, G. Pushing the Envelope: A NASA Guide to Engines; EG-2007-04-013-GRC; NASA: Washington, DC, USA, 2007.

15. El-Sayed, A.F. Fundamentals of Aircraft and Rocket Propulsion; Springer: London, UK, 2016.

16. Neill, S.M.; Pesyridis, A. Modeling of Supersonic Combustion Systems for Sustained Hypersonic Flight. Energies 2017, 10, 1900. [CrossRef]

17. Baidya, R.; Pesyridis, A.; Cooper, M. Ramjet Nozzle Analysis for Transport Aircraft Configuration for Sustained Hypersonic Flight. Appl. Sci. 2018, 8, 574. [CrossRef]

18. Roy, C.J.; Blottner, F.G. Methodology for Turbulence Model Validation: Application to Hypersonic Flows. J. Spacecr. Rockets 2003, 40, 8-11. [CrossRef]

19. ANSYS. Workshop 2-Transonic Flow Over a NACA0012 Airfoil. 2010. Available online: http:/ /imechanica. org/files / fluent_13.0_workshop02-airfoil.pdf (accessed on 19 January 2017).

20. Murugesan, S.; Dilip, A.S.; Nirmalkumar, D. Computational Analysis of Scramjet Inlet. Int. J. Recent Sci. Res. 2015, 6, 3391-3403.

(C) 2018 by the authors. Licensee MDPI, Basel, Switzerland. This article is an open access article distributed under the terms and conditions of the Creative Commons Attribution (CC BY) license (http://creativecommons.org/licenses/by/4.0/). 